University of San Diego

Digital USD

1988

\title{
An Analysis of Selected California Community College Chief Executive Officers' Perceptions of the Effectiveness of District Governing Board Evaluation Policies and Practices
}

Sherrill Lea Hatfield Amador EdD

University of San Diego

Follow this and additional works at: https://digital.sandiego.edu/dissertations

Part of the Leadership Studies Commons

\section{Digital USD Citation}

Hatfield Amador, Sherrill Lea EdD, "An Analysis of Selected California Community College Chief Executive Officers' Perceptions of the Effectiveness of District Governing Board Evaluation Policies and Practices" (1988). Dissertations. 510.

https://digital.sandiego.edu/dissertations/510

This Dissertation: Open Access is brought to you for free and open access by the Theses and Dissertations at Digital USD. It has been accepted for inclusion in Dissertations by an authorized administrator of Digital USD. For more information, please contact digital@sandiego.edu. 


\title{
AN ANALYSIS OF SELECTED CALIFORNIA COMMUNITY COLLEGE CHIEF EXECUTIVE OFFICERS' PERCEPTIONS OF THE EFFECTIVENESS OF DISTRICT GOVERNING BOARD EVALUATION POLICIES AND PRACTICES
}

\author{
by
}

Sherrill Lea Hatfield Amador

A dissertation submitted in partial fulfillment of the requirement for the degree of

\author{
Doctor of Education \\ University of San Diego
}

1988

Dissertation Committee
Wallace Cohen, Ed. D., Director Edward Kujawa, Ph. D. Ivan L. Jones, Ed. D.


(C) Copyright 1988

Sherrill Lea Hatfield Amador

All Rights Reserved 
DEDICATION

\author{
To my parents, \\ Don and willene Hatfield \\ who, throughout my life, have encouraged me \\ to do my best. \\ To my children, \\ Eric and Reyna \\ who will no longer be able to say, \\ "Mom, when are you going to finish your doctorate?" \\ and to
}

Ben Amador

my friend, husband, lover and confidante

who has stood by me through this endeavor

and all others I have attempted

and

has given me love and encouragement

when I needed it the most.

ii 


\section{ACKNOWLEDGEMENTS}

Many people were involved in bringing this dissertation to its fruition.

The staff at Southwestern College:

- . The Learning Resource Center, Library, and Computer Services staff, who provided valuable technical assistance.

- . Joe Conte, my chief executive officer, who gave his support and recommended my sabbatical to the governing board.

- .Ed Thorton, who proofread my dissertation, but more importantly, was my mentor over the last 14 years.

- .Yulie Willey, my secretary and assistant whose help and secretarial skills have been extraordinary.

- .Johanna Paladino, who has been my friend and has helped me keep all challenges in perspective over the years.

My disseration committee, Ivan Jones and Ed Kujawa, and my chair, Wally cohen, who kept me on track and offered valuable advance along the way.

The University of San Diego for bringing theory to this practioner's life. 
DEDICATION ................. . .

ACKNOWLEDGEMENTS . . . . . . . . . . . . i ii

LIST OF TABLES . . . . . . . . . . . . . . xi

LIST OF APPENDICES . . . . . . . . . . . . xii

Chapter

I. STATEMENT OF THE ISSUE ........... 1

Background ............. . 1

Evaluation of the Chief Executive ..... 2

Chief Executive officers'

Evaluations in California ...... 4

Evaluation for the Improvement
of Performance...... 5

Purposes of the study . . . . . . . . 6

Need for the study ......... . . 6

Research Questions . . . . . . . . 9

Definition of Terms ........ 10

II. REVIEW OF THE LITERATURE . . . . . . . . 11

Introduction ........... 11

The Evaluation Process . . . . . . . 12

Purposes for Evaluating Employees . . . . 13

Employee Performance Evaluation . . . . . 14

A Historical Perspective ...... 16

The Present Situation . . . . . . 16

iv 
Managerial Performance Evaluation . . . .

A Historical Perspective . . . . . . 19

Management by objective . . . . . . 20

summary . . . . . . . . . . . . 21

The Evaluation of the chief

Executive officer . . . . . . . . . . 22

Organizational setting . . . . . . . . 23

External and Internal Environment . . . 26

Governance Structures . . . . . . . 27

Chief Executive officer and Governing Board Roles in the Evaluation Process . . . . 30

Chief Executive officer Role and

Evaluation ......... . . 30

Roles of manager, leader

or administrator . . . . . . . . 31

Multiple and complex roles . . . . . 33

Governing Board Role and Evaluation . . . 35

Primary roles . . . . . . . . . 36

Changing board members . . . . . . 37

Purposes for Chief Executive officer

Evaluations .............. 38

Collegial Purpose . . . . . . . . . 39

Bureaucratic Purpose . . . . . . . 40

Political Purpose . . . . . . . . . 41

Formative and Summative Purposes . . . 43

Form and content of the Chief Executive

Officer's Evaluation by the

Governing Board.... . . . . . . . 43

Formats of Chief Executive officer

Evaluations .......... . . . 44

Collegial purpose format . . . . . . 44

$\mathbf{v}$ 
Bureaucratic purpose format . . . . . 45

Political purpose format . . . . . 45

Criteria for Chief Executive officer

Evaluations ............. 46

Individual and institutional criteria . 47

Determination of criteria . . . . . 48

Informal and Formal Evaluations . . . . 49

Informal evaluation . . . . . . . 49

Formal evaluation .. . . . . . . 50

Summary . . . . . . . . . . . . . 53

The Evaluation of the community college

Chief Executive officer . . . . . . . . 54

organizational setting . . . . . . . . 54

Roles of the Chief Executive officer

and the Governing Board . . . . . . . 56

Form and content of the chief Executive

officer's Evaluation ......... 58

Summary . . . . . . . . . . . 59

Summary of the Review of the Literature . . . 60

III. RESEARCH DESIGN AND METHODOLOGY . . . . . . . 62

Research Design . . . . . . . . . . 62

Site Selection and Sample . . . . . . . 64

Site selection .. . . . . . . 65

The Sample . . . . . . . . . . 66

Data Collection . . . . . . . . . 67

Interviews . . . . . . . . . . 67

Pilot Study . . . . . . . . . . . . 69

Interview Procedure . . . . . . . . 69

vi 


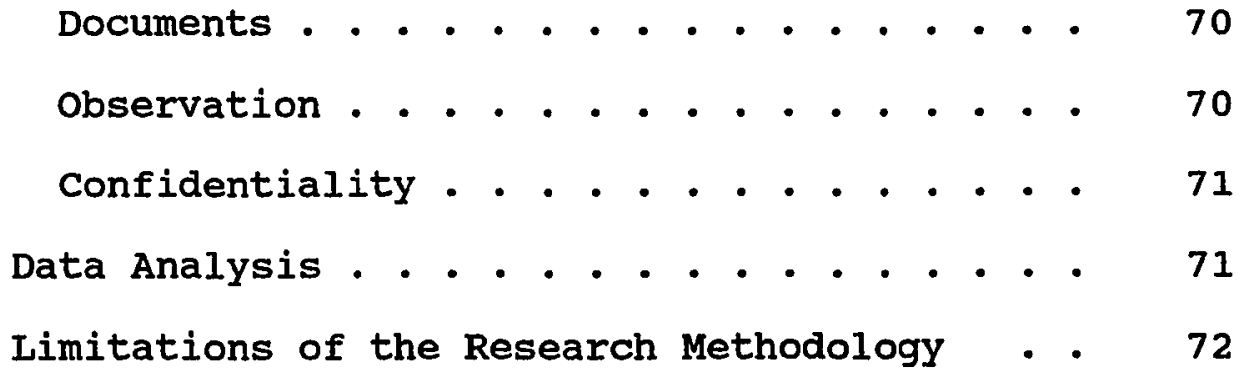

IV. ANALYSIS OF THE DATA . . . . . . . . . . . 74

Introduction . . . . . . . . . . . 74

Present Policies and Practices for

Evaluating Chief Executive officers . . . . 75

Form of the Chief Executive Officers'

Evaluations . . . . . . . . . . 75

Annual and Unwritten Evaluation Policies and Practices . . . . . . 75

Initiation of the policy or practice . 76

Formats of the Chief Executive Officers' Evaluations . . . . . . . . . . 77

Chief executive officer style and format of the evaluation . . . . 77

Settings of the Chief Executive Officers' Evaluation Meetings . . . . 79

Content of the Chief Executive officer's

Evaluations . . . . . . . . . . . 82

Feedback Channels Used by the
Governing Board . . . . . . . . 82

Chief executive officers' feelings on informal channels... . . . . . 84

Knowledge of chief executive officers' performance ... . . . . . . 85

Purposes for Evaluating Chief Executive officers ................ 86 Collegial purposes . . . . . . . 86 Bureaucratic purposes . . . . . . 86 vii 
Political purposes . . . . . . .

Criteria for Evaluating the Chief

Executive Officers . . . . . . . .

Formal and informal criteria used to evaluate the chief executive officers . . . . . . . . . . . .

Criteria which should be used to evaluate chief executive officers. .

Formal and Informal Chief Executive

Officer Evaluations . . . . . . . . .

Effective California Community College

Chief Executive Officers' Evaluation

Policies and Practices . . . . . . . . 94

Governing Boards' Role in Evaluation . . . 95

Governing Boards' Role as Evaluators . . 95

Fairness of the Governing Boards'

Evaluations . . . . . . . . • . 96

Chief Executive Officers' Evaluations and

Improvement of Performance . . . . . . 97

Evaluation Should Change Behavior . . . 97

Evaluation Changed Behavior . . . . . 99

Chief Executive Officers' Knowledge

of their Performance . . . . . . . 99

Specificity of Governing Boards'

Evaluation Suggestions ...... 100

Chief Executive officer Identified

Effective Policies and Practices . . . 101

Effective Policies . . . . . . . 101

Effective Practices . . . . . . . . 102

Chief Executive officer Identified

Evaluation Factors Contributing to

Effective Evaluations . . . . . . . . 103

Factors Affecting Chief Executive Officers' Evaluations . . . . . . . 103

District organizational Settings . . . 104 viii 


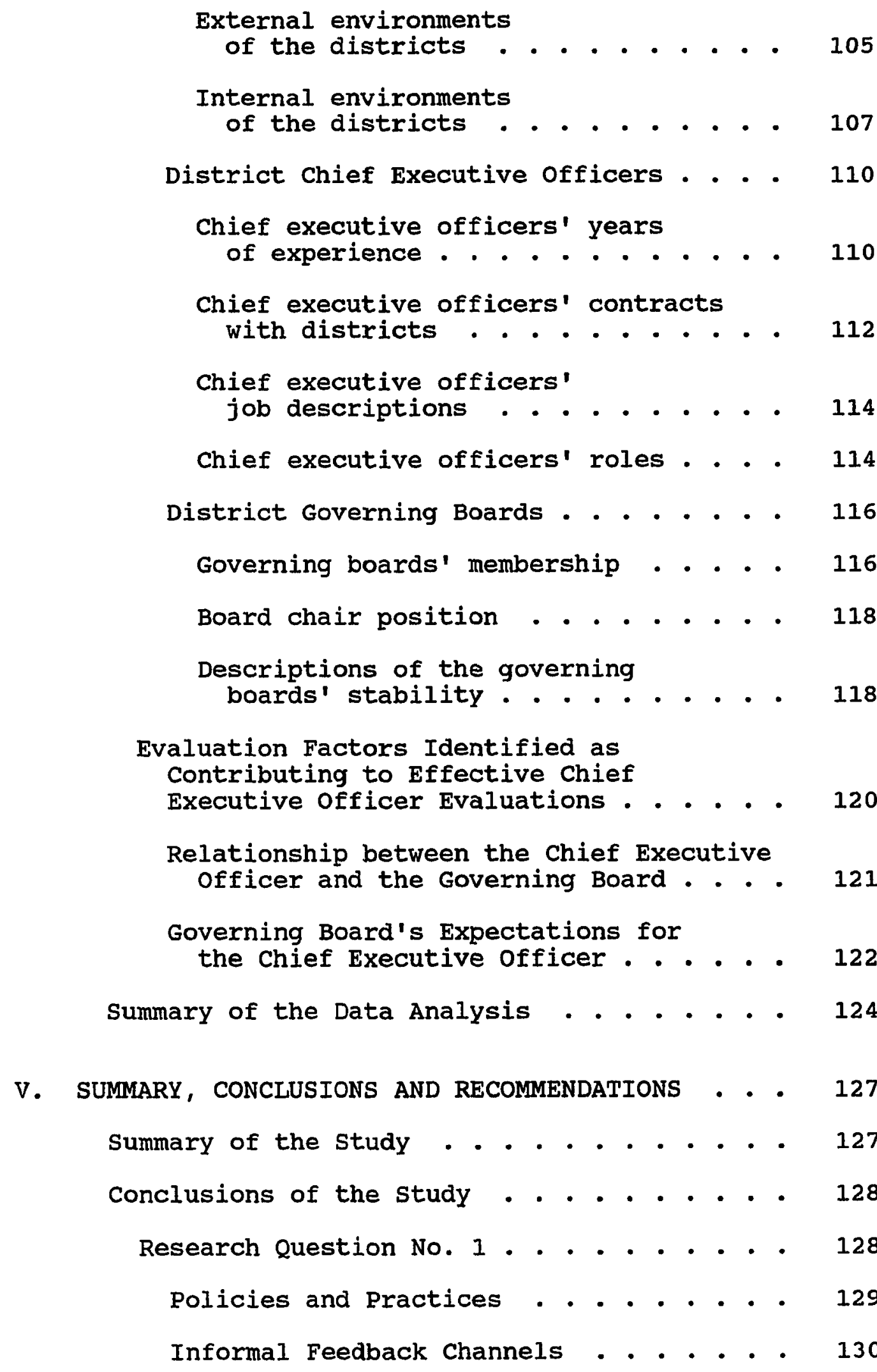

ix 


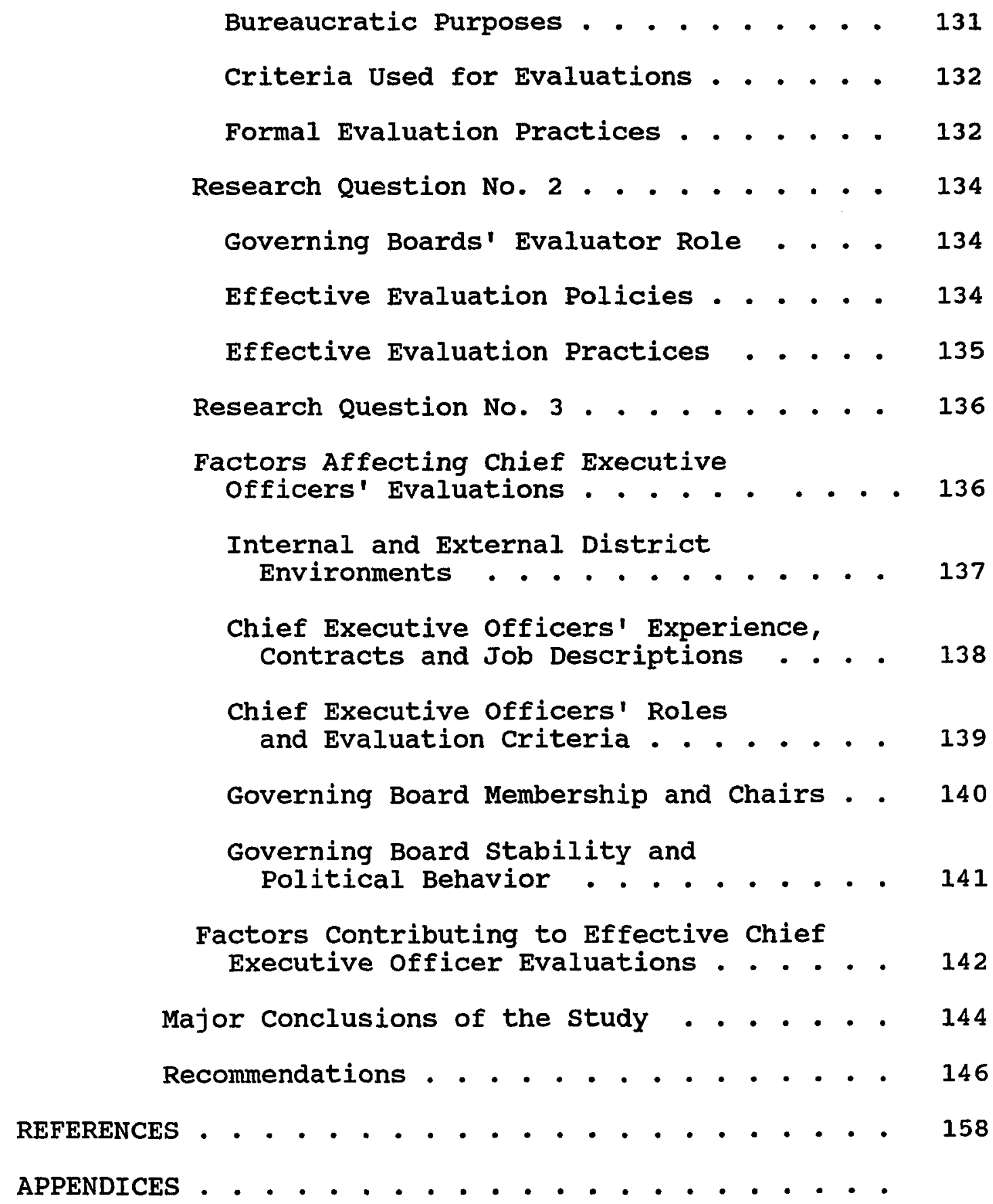




\section{IIST OF TABLES}

Table

Page

1. Frequency on Formats of Chief Executive

Officers' Evaluations .............

78

2. Settings of Chief Executive Officers' Evaluation Meetings . . . . . . . . . 80

3. Sample Districts' Student Body Size . . . . . 105

4. Governance Structures and Evaluation Effects . - 108

5. Years of Experience as District Chief Executive officer............. 110

6. Chief Executive Officers' Years of Experience as Community College Administrators . . . . . 112

7. Type and Length of Chief Executive officers' Contracts................ 113

8. Self-Described Chief Executive officer Roles . . 115

9. Board Member Changes During Tenure of Chief Executive officer . . . . . . . . 117 
LIST OF APPENDICES

Appendix

Page

A. Interview Request Cover Letter . . . . . . . 160

B. Letter of Support for Interview . . . . . . . . . 162

c. Structured Interview Questions . . . . . . . 164

D. Informed Consent Form . . . . . . . . . . 167

xii 


\title{
Chapter I \\ STATEMENT OF THE ISSUE
}

\begin{abstract}
Background
American community colleges began as junior colleges in the earlier part of the twentieth century. Beginning in the 1950s the function of the junior colleges broadened from providing primarily lower division transfer curricula to becoming comprehensive community colleges to serve the educational needs of their local communities (Vaughan, 1985). Today there are over 1100 public community colleges nationwide with 106 in California. These community colleges are organized into districts with locally elected or appointed governing boards. Seventeen states have boards elected by the citizens of the community college district (Gleazer, 1985, p. 47); California is one of these. A governing board establishes policy for the district and employs a chief executive officer as its legal head. Other terms used to refer to the community college chief executive officer are chancellor, president and superintendent.

The 70 California community college districts are regulated primarily by Title III of the California Education code (1983). The code stipulates that the chief executive officer shall have a personal services contract
\end{abstract}


with the community college district. Among the district governing boards' major responsibilities are the selection, evaluation, and termination of the chief executive officer (Cohen \& Brawer, 1982).

Evaluation of the Chief Executive officer

The relationship between the board and its chief executive officer is becoming more formal, contractual, and short-lived; therefore, boards faced with the prospect of contract renewal have a greater need than before to assess a president's performance (Beaudoin, 1986, p. 50). If the role of chief executive officer is one of service, and if the chief executive officer serves at the pleasure of the board, then the governing board must assume full responsibility for the adequacy of the chief executive officer's assessment (Kauffman, 1980, p. 94).

Chief executive officers have always been subject to informal review no matter where they are, but the formal assessment movement became a part of most of their careers in the late 1960s and 1970s (C. F. Fisher, 1978; J. L. Fisher \& Queh1, 1984; Kerr, 1984). The changing attitudes toward the evaluation of chief executive officer have been a response to a more general concern for assessment in higher education. Fisk and Richardson (1979) stated: This concern is partially motivated by a demand for accountability both internally from an increasingly powerful faculty and externally from legislatures and the general public. simultaneously, there has been an 
increase in the power, importance and complexity of the role of chief administrator (p. 342). Formal review and assessment of the chief executive are a response to public pressure for accountability.

Beaudoin (1986) suggested "public institutions are to some degree invaded by political accountability and, therefore, are more pressured to assess their leaders in a public way" (p. 11). "The accountability which has become the anticipated norm in the operation of community colleges is in keeping with the responsible approach that is expected from all public institutions in the 1980s" (Wattenbarger, 1983, p. 45).

There are conflicting views, however, on whether public performance reviews of the chief executive are the appropriate activity to insure accountability. Block (1979) a proponent of the State University of New York public presidential evaluation system commented: The danger is the tendency to evaluate presidents onedimensionally. Despite the dangers, the frustrations, the criticisms, the recommendations for changes in process, there has been widespread support for the overall concept of presidential review. In this age of accountability, evaluation of top leadership in educational institutions is a necessity (p. 154). Nason (1984a) cautioned:

Accountability is essential, but some kinds of accounting do more harm than good. This may well be the case with formal assessments, and we may see a 
decline in their popularity as rapid as their recent appearance on the academic scene (p. 1).

Beaudoin (1986) found that both presidents and governing boards have doubts as to whether performance reviews strengthen the president's academic leadership (p. 13). Chief Executive officers' Evaluations in California

Although there has been a national trend since 1980 toward formal, public assessment of the chief executive officer, there has not been a significant change in the methods California community college governing boards use to evaluate the chief executive officer. Scheidt's (1980) survey of 35 of the 70 California districts indicated $42.8 \%$ of the governing boards had no written policy for evaluating the chief executive officer. Another $28.6 \%$ indicated informal evaluation procedures were used, and 28.6\% had written evaluation policies or instruments. In Michael's (1985) survey of 59 of the 70 districts, he found that $6.8 \%$ of the governing boards did not evaluate the chief executive officer, $72.8 \%$ evaluated informally, and $20.3 \%$ used a specific evaluation instrument. Informal evaluation ranged from having no specific form or guidelines to an annual evaluation using a special format or objectives as a basis.

Volhontseff (1987) found in her study on California community college chief executives' evaluations that $82.7 \%$ of the 52 responding districts limited the evaluation to a process between the chief executive officer and the governing board instead of a formal procedure which 
involved other groups. In the same study, $61.4 \%$ of the districts used an informal system to evaluate the chief executive officer. (p. 51)

Hubert (1986) found in his study of California college and university presidents that $76 \%$ of the 58 community college districts responding used an informal format to evaluate their presidents, $17 \%$ used a casual format, $7 \%$ used a borderline format, and no district used a formal format. (p. 108)

Evaluation for the Improvement of Performance

The term evaluation implies that collected data will be used to make a value judgment and to pronounce an opinion following an inquiry or some deliberation (Beaudoin, 1986, p. 5) "The purpose of an evaluation is a constructive one and is intended to help the person evaluated to be more effective" (Van Cleve, 1983, p. 26). The primary purpose of an effective evaluation of a community college chief executive is to help the individual improve his or her job performance and satisfaction (C. F. Fisher, 1978, p. 7). "The aim of the evaluation is the improvement of the performances of both the administrator and the institution" (Potter, 1979, p. 55).

Even though governing boards are evaluating the chief executive officer and in many instances using a formal assessment procedure, few have asked whether the practices used are effective and strengthen the position. "To date, presidential assessment appears to be another one of those 
largely unexamined truisms of higher education" (J. L. Fisher \& Quehl, 1984, p. 5).

This study examined the issue of district governing boards' policies and practices for evaluating California community colleges chief executive officers and the effectiveness of the evaluations for improving their performance as perceived by the chief executive officers.

\section{Purposes of the study}

The purposes of the study were to:

1. determine the present governing board policies and practices for evaluating 20 selected California community college chief executive officers; and

2. identify those evaluation policies and practices which, from the perceptions of the 20 selected California community college chief executive officers, have effectively improved their performance; and

3. identify and analyze the factors which contribute to effective evaluations by improving the performance of California community college chief executive officers as perceived by the subject chief executive officers.

Need for the study

Surwill \& Heywood (1976) at the time of their study indicated that presidential evaluations were a neglected research area. Carbonne (1981) suggested that because the selection process for a chief executive officer was long and involved and the length of service short; there was a 
need to study the evaluations of chief executive officers of postsecondary institutions (p. xii). Potter (1979) stated:

Among the most important responsibilities of a community college board of trustees is the selection and evaluation of the college's president. Unfortunately, while a great deal of attention has been paid to the selection of this individual, the literature on proper evaluation of the college president has been slight (p. 55). Several conditions exist which created a need for this study:

1. The subject of educational chief executive officer evaluations is relatively a new one. Dick (1978) found no literature that seriously dealt with the subject prior to 1973 (p. 2). "There is a void in the literature on the assessment of community college presidents. One reason is that there is little formal assessment of presidential performance or formal evaluation of the community college presidents being done" (Williams, 1977b, p. 8). There has been limited research on the subject of community college chief executive officer evaluations, and more specifically, California community college chief executive officers. Both computer and library searches revealed only two studies dealing directly with the evaluation of California community college chief executive officers, Hubert (1986) and Volhontseff (1987). 
2. The research that has been conducted on the evaluation of college presidents and chief executive officers has been concerned with the form and content of the evaluation, not whether the evaluation was viewed as effective by the chief executive officer or the governing board (Beaudoin, 1986; Hubert, 1986; and Volhontseff, 1987).

3. The literature on the research subject was not definitive as to what constitutes an effective or model community college chief executive officer evaluation. In the Special Committee Report on Presidential Evaluation by the Association of Community College Trustees (1986) this statement was made: "Community college board members and chief executives alike recognize the importance of a professional approach to the evaluation of a chief executive, but few exemplary approaches can be found among American two year colleges" (p. 1). "It is becoming more and more important in a time of accountability that the chief executive officer and his board of trustees agree upon effective measures of evaluating each other's performance" (Lahti, 1973, p. 8).

4. The literature consisted mainly of a few governing board members and chief executive officers' opinions on the subject, not research studies. Fisk and Richardson (1979) stated:

Open discussion and surveys of opinion as well as informal reports of attempted uses of evaluation procedures account for most of the activity 
surrounding the issue of how best to evaluate the chief executive. Little systematic research either of a descriptive or an experimental nature has been undertaken (pp. 342-343).

5. This researcher through professional experiences has heard chief executive officers and governing board members express concern that there appears to be no current information at their disposal on effective practices or positive models for governing boards to follow to evaluate chief executive officers. Yet, each group appears to realize the serious consequences of a poorly designed and administered evaluation.

\section{Research Questions}

The specific research questions answered by this study were:

1. What are the present policies and practices being used by the 20 selected California community college district governing boards to evaluate their chief executive officers?

2. Which California community college chief executive officer evaluation policies and practices, of the 20 selected districts, are perceived by the chief executive officers to effectively improve their performance?

3. What factors contribute to effective evaluations by improving the performance of california community college chief executive officers, as perceived by the chief executive officer? 
Definition of Terms

The literature on college and community college chief executive officers' evaluations uses these terms interchangeably: chief administrator, chief executive officer, chief executive, chancellor, president, superintendent and superintendent/president. Also, the terms assessment, evaluation, performance review and review are used interchangeably. For the purposes of this study these definition of terms will be used:

Community College Chief Executive officer

The legal head of a community college district, also referred to in the California state Education Code as the district superintendent.

Multi-College and Multi-Campus District

A community college district that has at least two campuses, colleges or sites which may or may not have individual administrators, but constitute one district administration with a chief executive officer who reports to the governing board.

Single-College District

A community college district that is a college and district administration combined that is headed by a superintendent/president who reports to the governing board. 


\section{Chapter II \\ REVIEW OF THE LITERATURE}

Introduction

The purpose of this literature review is to provide a theoretical foundation for understanding the process for evaluating a chief executive officer in a postsecondary institution, and more specifically, for governing boards' evaluating California community college chief executive officers.

The review of the literature for this study is organized into three parts: (a) the evaluation process in an organizational setting with the distinction made between the evaluation of employee performance and managerial performance; (b) the evaluation of the chief executive officer focusing on the factors of the postsecondary institution's environment and governance structure, the roles of the chief executive officer and the governing board, the purposes for chief executive officer evaluations and the form and content of the evaluations; and (c) the evaluation of the community college chief executive officer with emphasis on California. 
The Evaluation Process

Several terms are used in the literature to denote the activity or process for evaluating people in an organizational setting; and most of the authors reviewed in this chapter used the terms interchangeably. These terms are appraisal, assessment, feedback, review, measurement, and evaluation with the added modifiers personnel, employee, managerial and performance. Depending upon the combination of the terms used, different emphases may be placed on the evaluation process. The terms appraisal and assessment have a more positive connotation in that they infer an estimation or taking into account of the person's strengths and weaknesses followed by constructive criticism which is intended to improve performance (Beaudoin, 1986, p. 5). The terms performance measurement and evaluation infer a judgment or decision on a person's performance. Losak (1975) made a further distinction between measurement and evaluation by suggesting that measurement can be value free and objective; whereas evaluation is never value free, nor thoroughly objective. For example, 'the typist can produce 10 pages of text with $98 \%$ accuracy in one hour' is a measurement of performance; whereas 'the typist is very fast and accurate' is an evaluation of performance. "Evaluation means to judge the worth of, to estimate the importance to, etc., and the evaluation processes are always pervaded by human judgment, with all the attendant bias and prejudice impled by that term" 
(Losak, p. 3). It is generally recognized that when humans are evaluating humans, the practice becomes less than precise. "Performance appraisal is similar to communications in that it is a vital process in organizations but is generally poorly handled" (Carlisle, 1987 , p. 388). As Klingner (1980) observed, "even though the appraisal or evaluation function is related to employee productivity and the employee's desire to know how well they are doing, rarely are supervisors or employees satisfied with the appraisal process" (p. 253).

\section{Purposes for Evaluating Employees}

There appears to be a general dissatisfaction with employee performance reviews because of lack of agreement on their purpose. Rice (1985) questioned the multiple purposes of evaluation reviews:

Should they merely evaluate performance, or critique and improve it as well? Should they be used primarily to determine salaries and prospects for promotion, or as a means of training and career development? Should they focus on how an employee does the job or the results achieved? Just who are they supposed to help, the employee or the supervisor? No performance review system can accomplish all these goals, but confusion about conflicting purposes often undermines attempts at effective evaluation (p. 31-32).

The general and multiple purposes of employee performance evaluation as summarized by Carlisle (1987, p. 389) and Klingner (1980, p. 254) are to: 
1. communicate management goals and objectives to employees and keep them informed on how they are achieving them.

2. motivate employees to improve their performance.

3. distribute organizational rewards such as salary and merit pay increases and promotions equitably.

4. recognize barriers or problems to improved performance.

5. identify training needs.

6. conduct personnel management research to discover ways in which performance can be improved both in relation to the individual and the work unit.

Tyer (1982) found in his survey of the 50 state governments that the most valued purpose of performance appraisal was the communication achieved between the employee and supervisor (p. 208).

\section{Employee Performance Evaluation}

Managers and supervisors are the people in organizations who usually evaluate the performance of the employees. This manager-employee relationship in an organizational setting was found to be the prominent orientation of the literature on performance evaluation. The employee evaluation process falls within one or several of the functions performed by management. Daft (1988) placed employee evaluation within the organizing function and human resources; Massie and Douglas (1985), the staffing and controlling functions; Richman and Farmer (1977), the controlling function. Personnel administration 
is usually the group or department within an organizational setting which insures that employees are evaluated, but the actual evaluation of the employee is the responsibility of the employee's manager.

Performance evaluation is, according to Howell and Dipboye (1982):

Any systematic attempt to gauge how well a person is doing a job. Clearly, evaluation would be impossible or meaningless without some explicit specification of what one is expected to do. Unless the person being evaluated and the person rendering judgment agree on what the job entails, there is little chance for a fair or accurate appraisal. Thus, a job description is a prerequisite for performance evaluation (p. 178). Performance "evaluation can be defined as the process through which members of a work group assess individual contributions to outcomes. Effective evaluation requires open communication" (Fisk \& Richardson, 1979, p. 342). King (1984) stated:

Performance appraisal is not about forms. It is about managers and employees coming to a clear understanding of what needs to be done, communicating frequently about progress and finally appraising the results of their efforts. It is not a once a year event, we are talking about an on-going process, a way of managing for results (p. ix).

In summary, the employee performance evaluation process is open communication between the manager and the employee 
based on stated expected outcomes and a job description which occurs frequently and results in outcomes, not just a completed form.

\section{A Historical Perspective}

The formalization of employee performance evaluation in organizational settings, according to Landy, Zedeck and Cleveland (1983), began with Taylor defining performance using scientific management and the Gilbreths' establishing work measurement methods in the 1920s. In the 1930s and 1940s, research was devoted to formats, methods, and physical characteristics of performance measurement systems. In the 1950s wherry studied the evaluation rating scale process and its components.

Initially, the research on employee performance assessment methodology was trait oriented and it later evolved to behavior oriented with the development of the Behaviorally Anchored Rating scale approach used by the military and civil service. More recently, industrial psychologists have shifted their research to performance outcome measurement methodology for evaluating employees (Carlisle, 1987, pp. 389-392).

All three employee evaluation methods: trait, behavioral and outcome are still found in various formats and combinations in all organizational settings (Aldag \& Stearns, 1987, pp. 373-376).

The Present Situation

When it comes to employee performance evaluation there appears to be considerable interest and discussion, but no 
definitive answers or solutions. Tyer (1982) found that employee performance was the most widely discussed tools or facets of personnel management (p. 199). After reviewing over 300 evaluation studies found in academic and management journals since 1950, Rice (1985) concluded that there is no 'easy way' to get accurate and informative employee performance data and that there is no one evaluation system, format or scale which can work for all situations (p. 34). Nordvall (1979) stated:

The far more experienced world of business has not found evaluation systems that are broadly satisfactory. The dilemma of an evaluation system complex enough to limit subjectivity while simple enough not to be excessively time-consuming has not been solved. Nor is an early solution likely (p. 50). Rice recommended, however, that organizations design a system that is most appropriate for them because employee performance evaluation can help management reward top performance employees and make it clear to others why some employees are being rewarded and others are not.

\section{Managerial Performance Evaluation}

A distinction was made in the literature between evaluating employee or worker performance and managerial performance. Because the tasks performed by management are more complex and interrelated, the evaluation of managerial performance is different from employee evaluation, less defined and more difficult to perform (Klingner, 1980, p. 257; Tyer, 1982, p. 208). "Quite frequently, management 
performance is evaluated subjectively on an overall basis simply because no one knows what the appropriate components are" (Howell \& Dipboye, 1982, p. 195). Management is evaluated by determining if it has effectively attained the organizational goals through the efficient utilization of organizational resources (Certo, 1983). Carlisle (1987), McCorkle and Archibald (1982), Richman and Farmer (1977) and Sloma (1980) link the evaluation of managerial performance to the management function of planning which includes the important activities of setting and prioritizing organizational goals. It is management's responsibility to determine the goals for the organization, which then are translated into operational objectives (Carlisle). Management goals are the guidelines or criteria that are used as the basis for evaluating management (Certo). These goals are evaluated by the output of the organization (Richman \& Farmer).

From the business management perspective, the "ultimate test of the success of management ideas is the actual, long-run performance and results in operations in the competitive market" (Massie \& Douglas, 1985, p. 477), which means a bottomline profit at year end. For the educational institution or the non-profit organization, the test is somewhat different and not as easily determined. Richman and Farmer (1977) suggested that educational management should be evaluated on the processes that are used for setting goals and determining priorities for the expenditure of the resources received by the institution 
(p. 90). McCorkle and Archibald (1982) further clarified the evaluation of management in a non-profit institution by placing it within the management cycle: the planning for resource management and then assessing if the results desired in the planning process were achieved with the institution's limited resources (p. 17).

\section{A Historical Perspective}

The history of evaluating management performance, according to Dick (1978, p. 5), began with the United states military in 1813 with standard formats being developed by 1920 based on Taylor's scientific management theories. The United states Government has evaluated its administrators since 1853. Within business and industry, the practices for evaluating managerial performance follow the evolution of management theory (Warren, 1982, pp. 544545). The theories from Taylor's scientific management and the management of activities, Fayol's organization of work and Weber's bureaucratic management which included the division of labor and the social structure of an organization provided the theoretical framework for evaluating managerial performance. Later there was a shift from a focus on the expertise or the knowledge and skills of technical management to the psychology of individual managerial performance building on the work of Herzberg and MacGregor (Astin \& Scherrei, 1980).

In the 1950's Drucker, using the functional approach to management, introduced the concept of management by objectives as a method for top management to evaluate their 
managers. He combined the functions of planning and controlling (Rausch, 1980) by integrating a rational evaluation model with systems theory (Harvey, 1976). More recently, the evaluation of management has been tied to management development. Organizational process management joins the concepts of group behavior, leadership and organizational values in an open system to create an action plan for management development (Warren, 1982, p. 545). The focus is on the results desired by the organization, not just what is actually achieved; and organizational planning is tied to the evaluation of management through continuous feedback.

Management by objectives

Drucker's later work also incorporated management development into management by objectives by adding developmental goals to the manager's operational objectives (Rausch, 1980, p. 87). Drucker (1974) stated:

The greatest advantage of management by objectives is perhaps that it makes it possible for a manager to control his own performance. Self-control means stronger motivation: a desire to do the best rather than do just enough to get by. It means higher performance goals and broader vision (p. 439-440). Management by objectives based appraisal systems have become the most frequently used form of managerial and supervisory appraisal in business and industry (Thompson, 1981, p. 282). Also, management by objectives concepts and modifications of the concepts are used for evaluating 
management, support staff and faculty in higher education institutions (Losak, 1975, p. 1; Rausch, 1980, p. 85). Although there is widespread use of the management by objectives approach to evaluation, several authors were not sure it really works. The major criticisms of management by objectives are that it is difficult to set meaningful, quantifiable and fixed goals over time with changing conditions; it takes three to five years to implement; it creates a lot of paperwork and it is time consuming (Aldag \& stearns, 1987, p. 376). It is not compatible with the comprehensive and complex roles of upper management (Anderson, 1975, p. 43.). Also, because the approach does not help individuals analyze their motives for not achieving their objectives, it results in single loop learning with no individual growth and restricts creativity (Argyris, 1980, p. 35). Management by objectives is generally considered not to be an appropriate method for evaluating top management or the chief executive officer (Anderson, 1975; Harvey, 1976; Losak, 1975; Rausch, 1980) .

\section{summary}

The evaluation process in organizational settings has multiple meanings and purposes with the manager-employee relationship forming the foundation for the concepts and the many practices. The performance evaluation process is not precise because it involves human interaction and it becomes less defined and difficult to perform when the person being evaluated performs the complex tasks of management. 
The Evaluation of the Chief Executive officer The person in any organization with the least defined and the most important management position is the chief executive officer. Most of the literature on managerial performance focuses on how top management of an organization evaluates its line and staff managers' performance from the second level in the organization down through the line supervisors. This, however, is different from the evaluation of the chief executive officer.

At the chief executive officer level of an organization, the individual's performance encompasses both the performance of the organization and the management team as a whole, because the chief executive is responsible for the contributions of management and the results it has achieved (Drucker, 1974, p. 626; 1967, p. 53). It follows then that as we move up the organization, evaluation procedures can become less and less precise (March, 1984, p. 27) because it is difficult to separate the chief executive's performance from the performance of the organization.

There are several unique conditions present in postsecondary institutions that influence the evaluation of chief executive officers by governing boards. This portion of the review focuses on these conditions: the organizational setting, the roles of the chief executive officer and the governing board, the purposes for 
evaluating chief executive officers, and the form and content of the evaluations.

\section{organizational setting}

Postsecondary institutions are being influenced more than ever before by corporate attitudes toward management and accountability (Beaudoin, 1986, p. 58). When models for evaluation are sought, postsecondary institutions have looked to business for models (Nordvall, 1979, p. 49). Williams (1977a) cautioned, "if the vitality and health of the individual institutions are to be maintained, higher education's continued lag behind business and industry, in the assessment and development of its managers, must be addressed" (p. 4). Nordvall observed though, "higher education takes ideas from business, but cannot too openly acknowledge this borrowing lest the ideas be rejected as coming from an inappropriate source" (p. 49). There are reasons to question whether business is the appropriate source for evaluation models when several differences exist between business organizations and higher education or nonprofit institutions which affect the evaluation of the chief executive officer. Allison (1984) suggested that at the level of generality, management is management, whatever the organizational setting; but functions that have the same name take on different meanings depending upon whether the organization's goal is profit or non-profit (p. 219).

Kerr and Gade (1986) indicated there are vast differences between the corporate model and the higher education model; they are summarized below: 
1. Corporations have no tenured faculty with no guarantees of academic freedom to do or say whatever anyone may want to do or say.

2. A corporation has single-service customers with no students on the premises daily and no alumni.

3. Corporations are vertical, not horizontal in organizational reporting format, and the reporting channels are enforced.

4. A corporate board is made up of operating officers and others that are chosen by the chief executive.

5. A corporate chief executive has more control over the expenditure of his time.

6. A corporate chief executive has many internal sources of support versus the loneliness of a college chief executive.

7. A corporation has one bottomline and it is precise--profit, whereas the higher education institution has many.

8. A corporation can make or remake decisions constantly, whereas within an educational setting everyone needs to be consulted which causes delays. (pp. 38-39)

Sloma (1980) described the corporate board members as having as their main concern, the return on their investment, whereas a public board has no dollar investment (p. 8). Dressel (1981) made these distinctions between the corporate and higher education settings. The corporate board chair is usually the chief executive officer and the president is second in line, the career route to the chief 
executive officer position is being a member of the board of directors, the board members are a part of the organization and the workers of the corporation have structured jobs. In contrast, the higher education board chair is mainly a symbolic role. The chief executive officer or president serves at the pleasure of the board and the route to being a chief executive officer is through academic ranks. Members of the board and administration are kept separate. Additionally, the faculty perform the major work of the institution, but are in many ways autonomous. (pp. 183-184)

Both Anderson (1975) and Kerr and Gade (1986) agreed that the lateral and autonomous relationships of the faculty and their essential influence over the academic Iife of the institution are the greatest distinctions between a business organization and a higher education institution.

Higher education institutions have a greater multiplicity and diversity of objectives and criteria, a greater vagueness and intangibility of objectives and criteria and a greater tendency for the goals to be conflicting than do business organizations (Allison (1984, p. 223)

In addition to the differences between a business organization and a postsecondary institution discussed ... previously, the differing environment and governance structures of a postsecondary institution can be assumed to have a significant impact on the performance and the evaluation of its chief executive officer. 
External and Internal Environment

Bennis (1976) suggested that two conditions prevent one from being a good leader: the turbulent, unstable world with an explosively changing environment and the need to balance the interests and demands of internal constituencies while paying equal attention to external demands (p. 127). These conditions exist for the higher education institution chief executive as well. Kerr and Gade (1981) were referring to the college and university presidency when they described several conditions that make the position less tenable than in former times:

1. Management of decline is harder.

2. The power to make decisions affecting persons or groups within the institutions moves farther and further away from those affected.

3. The responsibility for what goes on in the institution is more diffused with the introduction of the spirit and mechanisms of participatory democracy.

4. The push for more centralization and accountability results in no one being accountable. (p. 128)

Later Kerr and Gade (1986) described the unionized college environment and the president's evaluation:

Faculties often are unionized and the unions sometimes control one or more, or even a majority, of the board members; and unions often practice confrontation with presidents and always support the introduction of negotiated rulemaking to replace presidential 
decision-making. The short-term production process leads to short-run tests of performance and sometimes to short-term presidencies (pp. 166-167).

Governing boards want an environment where the college mission is clarified through long-range planning, the budget is balanced and autonomy of the local board is maintained in states with system boards (Nason, 1981, p. 261). The chief executive officer must deal with both internal and external factors, with the latter becoming more important because of the scarce resources, which come from outside the institution (Mooney, 1988, p. A15). Given all of these conditions and expectations, Mccorkle and Archibald (1982) affirmed that the challenge for the college chief executive officers in the 1980s is to manage their environment (p. xvii).

Landy, Zedeck, and Cleveland (1983) stated that performance and its measurement in unstable environments needs to be situationally defined (p. 1). There was agreement among Fisk and Richardson (1979), Nordvall (1979) and Williams (1977a) that the history and environment of an institution must be considered when evaluating the chief executive officer and the evaluation should be limited to expectations that the chief executive has reasonable control over based on the present environment.

\section{Governance Structures}

According to Dressel (1976), "the evaluation of administrative effectiveness must be based to some extent upon some model which characterizes a particular 
institution. Several models have been developed or applied to institutions of higher education; none applies to any one institution" (p. 382).

The president at the top of a hierarchical pyramid is the classic model of college governance where "the president derives his or her authority from the trustees, but they [trustees] in turn are expected to rely on the president for guidance in all educational matters" (Nason, 1981 , p. 254). Nason also noted that this model no longer exists; governing boards have gained more control and shared governance exists between faculty and administration.

Baldridge (1971) provided three models of university/college governance structure depicting the basic image of each: (a) collegial, a professional community; (b) bureaucratic, a hierarchical structure; and (c) political, a political system (p. 25). Dressel (1976) added a fourth model to Baldridge's three: human relations, which places emphasis on human values and selfactualization (pp. 383-384). Bolman and Deal (1984), although referring to a corporate organization setting, developed similar governance approaches: (a) structural, emphasizing the organizing function; (b) human resources, fitting the organization to people, (c) political, recognizing power, conflict and coalitions; (d) symbolic, suggesting culture and ritual pervade all activities (Chap. 1). Bolman and Deal considered evaluation to be a symbolic process and stated, "evaluation is something that organizations need to do if they are to be viewed as 
responsible, serious and well managed, even though the results of evaluations are rarely used for decision making" (p. 179).

In 1974 Cohen and March (1986) characterized the academic institution as an organized anarchy with ambiguity as the basic property of the model, in particular when determining presidential success.

Richman and Farmer (1977) building upon contingency theory suggested a multidimensional governance model where institutional goal systems and priorities are of primary importance and conflict situations frequently result from goal divergence among different groups or constituencies both internal and external to the organization.

There was no real agreement on a higher education institution governance model among the various authors, although similarities and overlaps among the proposed models were evident. It is noted, however, that there was agreement among the reviewed authors that governance structures do exist and they have an influence on evaluation within an organization. As Dressel (1976) recommended, the evaluation of the chief executive officer "must take into account the peculiar character of higher education governance, the specific nature of the particular institution and the external pressures bearing on it" (p. 388) 
Chief Executive officer and Governing Board Roles

in the Evaluation Process

The roles that the cliief executive officer and the governing board play, whether evaluation is occurring or not, have a major impact on the chief executive officer's evaluation.

Chief Executive officer Role and Evaluation

The chief executive officer's multiple roles and the perceptions about these roles coupled with the lack of security that comes with the position complicates the evaluation of the chief executive officer in a postsecondary institution. Many roles have been attributed to the chief executive officer.

Kauffman (1980) described the role of the chief executive by the tasks of leadership; communication; and ritual management and control (pp. 13-14). He also added that the chief executive plays a vital political role (p. 58). Cohen \& March (1986) defined seven roles for the chief executive officer: manager, politician, mediator, chairman, entrepreneur, catalyst, judge, and philosopherking (pp. 38-40). Baldridge (1971) stated that the role of the chief executive is statesperson (p. 206). Wood (1984) indicated that the presidential selection process, which results in a compromise candidate, causes the president to assume a political role while at the same time the expectation from the board will be a bureaucratic/managerial role (pp. 39-40). Hansen (1984) stated that the evaluation of the president politicizes the president's role: 
Making decisions for the good of the institution will always appear to some to be either self-serving or narrowly biased. And giving people within the institution an opportunity to point that out will not change the reality that not everyone can or will be pleased either by the decisions the president makes or the leadership style in which that is done (p. 8) Bolman (1965) suggested that the role of the chief executive and the requisite personal characteristics required to perform the job will vary according to the needs and aspirations or the environment of the particular institution.

Roles of manager, leader or administrator. Several authors agreed that the chief execitive officer's role, which is dictated by the environment of the educational institution, is one of manager. "The chief executive officer is responsible for managing the institution" (Lahti, 1973, p. 7) . Benezet, Katz and Magnusson (1981) determined from their study, "Today's president. . . inherits a structure [hierarchical] that mandates a managerial role" (p. 42). They stated:

Books written during the past twenty years underscore a continuing trend: the office of president is seen as declining in educational significance while becoming more and more managerial (p. 2). . . Most presidents struggle for a compromise position between manager and education leader, a position that because 
of the financial problems weighing on the school, becomes harder to maintain every year (p. 7).

In 1962 Dodds questioned whether the president ought to be primarily an educational leader or an institutional manager/caretaker, since it requires managerial responsibility to delegate authority to individuals who will see to the performance of particular operations (Anderson, 1975, p. 55) . Building upon Burn's (1978) leadership theory, Kerr and Gade (1986) suggested that during normal times, boards and faculty selection committees are more likely to choose managerial (transactional) leaders than pathbreaking (transforming) leaders because they usually are more interested in good management than in transforming their institutions. Also, boards and committees want predictability in their presidents (p. 71).

Benezet, Katz and Magnusson (1981) also found: A president who desires to be a leader in education must reconcile that desire with the necessity of being a manager. During our interviews, it became progressively clear that educational leadership and management are no longer considered mutually exclusive tasks (p. 49).

Seitz (1980) stated this compelling syllogism, "administration is a social function; college presidents are administrators; therefore, college presidents must be appraised in terms of their social interaction" (p. 28). He then countered with the concern that using only social 
interaction can lead to a popularity contest and not an evaluation of performance.

Millett (1980) suggested that the administrative role of the president is to link management with governance and performance with decisions, and called that administrative role 'leadership' (pp 111-112). Dressel (1976) indicated there are problems with evaluating the chief executive as an administrator because administration is related to both leadership and management. He recognized that distinct differences exist between leadership and management which result in no clear or generally accepted criteria for success when evaluating the chief executive (pp. 377-378). Cyert (1980) also noted that it is possible to be an effective manager without being an effective leader. Richman and Farmer (1977) contended that colleges and universities need professional managers more than competent administrators (p. 15). Benezet, Katz and Magnusson (1981) stressed that the chief executive's managerial skills should be the main elements in evaluating performance, even though the faculty may look for educational leadership when they participate in the chief executive's evaluation (pp. 46-47). Multiple and complex roles. The college constituencies' perceptions of the chief executive officer's roles and the performance of those roles, rather than actual facts, become critical to the evaluation of the chief executive. What is needed is an evaluation process that involves clarifying role expectations and gathering, analyzing, and weighing information on the chief 
executive's performance (Farmer, 1979, p. 4). But Evans, Mears, \& Wattenbarger (1979) found when developing their chief executive officer evaluation instrument:

The complexity of the job of the president almost defied an objective measurement of most of the functions. Also, it was recognized that the overall effectiveness of a president rests in large measure on how he is perceived to be carrying out his/her job by persons in the immediate environment (p. 66). It is interesting to note, however, that paxton and Thomas (1977) found in their study of presidential leadership: From the faculty's point of view there are not many and varied dimensions of the presidential role. Rather, faculty tend to respond to a variety of different items on the basis of only three underlying dimensions: personal-public image, faculty-student interaction with presidents and absence of autocratic leadership style (p. 350) . Kauffman (1980) suggested another role for the chief executive to assure that evaluation is based on performance:

A president must not refrain from playing the role of teacher with a governing board, increasing members' understanding, suggesting proper boundaries between the respective roles, and providing constant feedback to improve the performance of both the board and the president ( $p .56)$. 
"Increasingly presidents are taking the leadership in initiating discussion about evaluation procedures with their boards. . . From a pragmatic perspective, presidents also initiate discussions of evaluation procedures in order to have input into a process which appears inevitable" (Fisk \& Richardson, 1979, p. 343). The paradoxical role position of the chief executive officer as the educator of the governing board and the primary agent for the governing board presents a conflict for both the chief executive and the board when the chief executive is evaluated (Beaudoin, 1986; Munitz, 1978, 1980; Nason, 1984a).

"Trustees need to be sensitive to this gap between expectations and realities in deciding when to review presidential performance and what areas of the institution's operations to examine" (Beaudoin, 1986, p.16). Having multiple and complex roles with no real agreement on which role or roles will be evaluated places the chief executive officer in a very insecure position. Kauffman (1980) summarized the dilemna:

The college and university presidency is an anomalous role, for no career line serves as preparation for it. Nor does the position carry security; the president serves "at the pleasure of the board"--the average length of service is five years ( $p$. ix). Governing Board Role and Evaluation

Public and private lay boards are an accepted part of 
American higher education governance (Kauffman, 1980, p. 53). To understand the board's role in evaluation of the chief executive officer, it is necessary to recognize that publicly elected governing boards, found in California community colleges, tend to be more political public servants; and therefore, less effective than private boards who are usually selected or appointed by the chief executive officer or local and state officials (Kauffman, 1980; Kerr, 1984; Nason, 1984a). Elected boards tend to represent the people who elect them; tend to have a special sense of control over the chief executive officer; and because they meet often have an opportunity for detailed participation in the management of the institution (Kerr \& Gade, 1986, p. 110). Gleazer (1985) commented on the changing role of boards:

Now, whether the trustees consider themselves sufficiently self-reliant or whether they are expressing the dynamics of social change, they appear more assertive, less likely to be awed by the president's knowledge, and they seldom see themselves in a subordinate role. The trustee role is becoming more prominent in the governance of the institution (p. 42) .

Primary roles. The governing board's primary roles are the selection, recurrent evaluation, retention and termination of the chief executive officer (Anderson, 1975; Dressel, 1981). The board's responsibility is to make sure the president is carrying out the policies adopted by the 
board (Nason, 1981, p. 261). The board acts as an advisor to the chief executive, but it also must remove the chief executive for lack of performance (Drucker, 1974, pp. 631632). The relationship between the chief executive officer and the governing board is a delicate one.

"Without a sound relationship with the governing board, the president cannot be effective" (Kauffman, 1980, p. 52). There must be mutual respect and trust between the board and the chief executive officer to insure a higher level of performance for the institution (Tatum, 1985, p. 18). Also, a supportive board is needed to promote a unity of purpose (Gilley, Fulmer \& Reithlingshoefer, 1986, p. 12).

Changing board members. Because of board elections, the longer the chief executive officer is in office the fewer board members remain who were serving at the time of the chief executive's selection and who shared in the setting criteria for that selection (Munitz, 1978). A change in the composition of governing board members can have an effect on "shared respect and confidence," the key ingredient to an effective chief executive officer and board relationship (Kauffman, 1980; Pullias \& Wilbur, 1984).

"Given the turnover on boards of trustees, especially in states with district elections, maintaining sound relationships is an incessant challenge" (Ingram, 1979, p. 75). The chief executive officer must cope with the fact that each board member has his or her own distinctive 
understanding of the institution's mission; and therefore, his or her own expectations of the president's performance (Munitz, 1978, p. 12). "The success of the periodic assessment [evaluation of the chief executive] may well center more on the nature of the individuals involved than the system itself" (Brown, 1984, p. 4). Tatum (1985) also commented, "no board member can assess a president with fairness and honesty without knowing what the trustee's job is all about" (p. 15) and suggested that this condition exists in many boards.

"Often, the governing board itself is a major factor in the president's effectiveness or lack of effectiveness" (Kauffman, 1980, p. 94). The governing board's ability to effectively perform its important role of evaluating the chief executive is affected by the multiple roles of the chief executive, the public nature of the elected board, and the personalities of the individual board members and the level of mutual trust that exists between the chief executive and the board.

Purposes for Chief Executive officer Evaluations

The main purpose of an evaluation is to respond "to an audience's requirements for information, particularly in ways that take account of the several value perspectives of its members" (Guba \& Lincoln, 1981, p. 36).

The audience of an institution and its values are manifested in its governance structure and environment. Drawing from the previous discussion in this chapter, there appears to be no agreement on a single college/university 
governance model. Most authors agreed, however, that several governance models exist and that more than one model may exist in any one institution at any time depending upon the issue and or circumstances. When the issue is the evaluation of the chief executive officer, the purposes of the evaluation are reflective of the governance model being used.

Baldridge's (1971) three models of university governance: collegial, bureaucratic, and political (p. 25) are used in this review to exemplify the governing board's purposes for evaluating the chief executive officer.

\section{Collegial purpose}

The professional development and improvement of performance of the chief executive officer was considered by many authors to be the primary purpose for evaluating the chief executive officer (Beaudoin, 1986; C. F. Fisher, 1978; Miller, 1979; Munitz, 1980; Schafer, 1980; Van Cleve, 1983; Wheat, 1981; Williams, 1977a). Wattenbarger stated: An effective evaluation plan is necessary because it provides a formal framework for the individual in an organization to discuss performance, achievements, and hindrances from a personal and individual point of view and from an organizational point of view (p. 47). The professional organizations of the Association of Community Colleges Trustees and the Association of Governing Boards support conducting an evaluation of the chief executive officer and state that the purpose is for 
the improvement of the chief executive and the institution (ACCT, 1986; Nason, 1984a).

Eureaucratic Purpose

Accountability was suggested as a major purpose for the evaluation of the chief executive officer by the governing board. Accountability for fiscal matters (Hubert, 1986), accountability to the public for maintaining the institution (Anderson, 1975; Brewster, 1970; J. L. Fisher \& Quehl, 1984; Henderson, 1976; Nason, 1984a; Volhontseff, 1987), and political accountability to the internal and external constituencies of the chief executive and the board (Beaudoin, 1986).

Schafer (1980) recommended evaluation for the purpose of results, which he considered a rational approach to evaluation of the chief executive. Evaluation by results, suggested Schafer would "get away from the accepted governance model which is more myth than reality, from decision making that is often more political than rational, objectives that are often in the eye of the beholder rather than observable for objective assessment" (Conference speech, March, 1980). Rational behavior is used for decision-making in Baldridge's (1971) bureaucratic governance model. other bureaucratic reasons to evaluate the chief executive include contract renewal, terms of reappointment, and salary (Beaudoin, 1986; Kauffman, 1980; Kerr, 1984; Wattenbarger, 1983). The Association of Governing Boards recommended, however, that evaluation should not be conducted on the basis for making a decision 
to retain or not retain the chief executive (Nason, 1984a). Beaudoin (1986), also observed that the "fear of litigation by some boards may lead them to evaluate as a means of collecting evidence to support their decision to reappoint, or dismiss, a president" (p. 6).

Political Purpose

The evaluation of the chief executive officer by the governing board is a symbolic act and motivated by politics (Beaudoin, 1986; Kauffman, 1978, 1980; Munitz, 1980). Guba \& Lincoln (1981) stated "evaluation has strong political overtones and that evaluation is itself a source of political power" (p. 298). The relationship between the chief executive officer and the governing board is political; therefore, objective evaluation of the chief executive will remain a myth (Lombardi, 1981). This political relationship dictates that both the chief executive and the board respond to constituencies. The faculty in many instances becomes the pressure group to respond to on such conflict issues as collective bargaining (Cyert, 1979) and a believed faculty "right" that has been abrogated (Kauffman, 1980). Wood (1984) suggested that this relationship results from shared governance in a political environment:

It seems that the relationship between the board and the president often proceeds on the basis, unspoken and unacknowledged, that no single president is likely to be able to make a critical difference in advancing the institution's welfare. Assuming it unlikely that 
substantial progress can be achieved during one person's tenure, governing boards tend to support most readily the president who succeeds on the one hand in avoiding significant antagonism, particularly from the faculty, and on the other hand, in functioning competently as a coordinator of vice-presidents perceived to be doing the substantive work of the college. These limitations are not imposed by the board on a naive and victimized incumbent; rather, they are the variables that each president develops into an equation for surviving the hazards of shared governance under highly politicized conditions. In this environment, some presidents have moments when they see themselves as journeymen and transients somewhat at the mercy of a governing board overly responsive to faculty and student complaints (p.42). Evaluation in a political environment may create the situation cited by Seitz (1980): "Getting along with everyone and being liked have gained more importance in some quarters than attaining institutional progress and organizational quality--the primary matters for which the chief executive is responsible" (p. 28). It may be politically unwise for the chief executive to speak against being evaluated for fear of being considered insecure, since "evaluation is a process that fosters belief, confidence and support from external constituencies and benefactors" (Bolman \& Deal, 1984, p. 180). "Indeed, the conventional wisdom today is for a college president to ask 
for, even demand, an assessment" (J. I. Fisher \& Quehl, 1984, p. 5)

\section{Formative and summative purposes}

Fisk and Richardson (1979) added two additional

purposes to chief executive evaluations: formative and summative. Formative evaluation lends itself to improved performance, whereas summative is judgmental and final.

"Most recent thinking seems to favor an emphasis on formative evaluation although both types are recognized as essential. The models of presidential evaluation currently in use combine aspects of both" (Fisk \& Richardson, p. 344).

Chief executives are evaluated for both single and multiple purposes which in turn influence and further complicate the form and content of the chief executive officer's evaluation by the governing board.

Form and Content of the Chief Executive Officer's

\section{Evaluation by the Governing Board}

A maior portion of the literature on chief executive officer evaluations centers on the form and content of the evaluation process. The approaches used to evaluate the academic chief executive correspond closely to those used to evaluate faculty and have evolved from the practices of evaluating faculty (Dressel, 1980, p. 202; Gephart et. al., 1975). "Administrative evaluation which include the evaluation of the president of a college or university, is an extension of the interest and work that has been done in student evaluations (1960s), faculty evaluations (1970s) 
and overall institutional assessment" (Williams, 1977a, p. 3). And as with faculty and administrative evaluations, there is no consensus in the literature on what constitutes the appropriate form and content for a chief executive officer evaluation by the governing board. Nason (1984a) suggested that the main issues the governing board should resolve on the evaluation of the chief executive officer are not whether to assess, but how to conduct the assessment; and what the assessment intends to accomplish (p. 9). "The danger is that some of our finest people will be driven away by crude assessment devices" (Munitz, 1978, p. 21). General suggestions were that the evaluation be a board function (Hanley, 1975; Munitz, 1980), occur in a trust relationship between the chief executive and the board (ACCT, 1986; Schafer, 1980) and take place annually with on-going communication (ACCT, 1986; Dressel, 1976; Tucker \& Mautz, 1979). Formats of Chief Executive Officer Evaluation The formats used to evaluate the chief executive officer cover a board range of activities. They are categorized below by the collegial, bureaucratic, and political purposes they achieve, using Baldridge's (1971) governance model.

Collegial purpose format. The formats with collegial purposes are:

1. Chief executive officer self-evaluation or assessment (Beaudoin, 1986; Kerr, 1984; King, 1984; Tatum, 1985; Williams, 1977a). 
2. Chief executive officer growth contracts and an ad hoc evaluation committee (Anderson, 1975; Farmer, 1979).

3. Administrative council evaluates chief executive in a separate internal feedback process from the governing board (Williams, 1977b).

4. Outside consultants perform an independent evaluation of the chief executive officer (Munitz, 1980; Fisk \& Richardson, 1979).

Bureaucratic purpose format. The formats with bureaucratic purposes are:

1. Rating scales assessing the chief executive officer based on some criteria (Bahar, 1979; Fisk \& Richardson, 1979; Hubert, 1986; Seitz, 1980; Wattenbarger, 1983; Williams, 1977a).

2. Chief executive officer job descriptions (Gleazer, 1985; Lahti, 1973; Seitz, 1980; Tatum, 1985).

3. Management by objectives (Hubert, 1986; Wattenbarger, 1983) and long-range planning (King, 1984; Lahti, 1973; Parekhi, 1977).

political purpose format. The formats with political purposes are:

1. Annual or biannual public reports presented by the chief executive (Gleazer, 1985; Kerr, 1984).

2. Joint chief executive officer and board goalsetting activities with an emphasis on resolving interest group conflicts (Baldridge, 1971).

Several authors stated that any evaluation of the chief executive can be political because of the political 
environment in which the chief executive and the board function (Beaudoin, 1986; Cyert, 1979; J. I. Fisher \& Quehl, 1984; Kerr, 1984; Kauffman, 1978, 1980; Seitz, 1980).

Using the premise that multiple formats and measures insure a more objective evaluation, many authors specified that more than one format should be used in the chief executive officer evaluation process (ACCT, 1986: Gleazer, 1985; Seitz, 1980; Tatum, 1985; Williams, 1977a). "The design of an evaluation program should be based on a recognition of its purposes although these are often so numerous and diverse that one procedure could not hope to adapt to them all simultaneously" (Fisk \& Richardson, 1979, p. 343).

\section{Criteria for Chief Executive officer Evaluations}

"The varying roles of the president compel multiple criteria for evaluation" (Nordval1, 1979, p. 43). Kauffman (1980) stated:

Because I believe that colleges and universities, as organizations, have multiple and ambiguous criteria for success, the presidents of such organizations also inherit that complexity and ambiguity when it comes to judging or assessing their own success (p. 93). McCorkle and Archibald (1982) suggested that confusion exists on the appropriate criteria for evaluating the chief executive officer; the reasons being a lack of clear assignment of responsibilities, an absence of definitive 
performance objectives, multiple reporting lines and shared governance (p. 154).

Individual and institutional criteria. The chief executive officer is evaluated on individual performance as well as institutional performance (Dick, 1978; Drucker, 1974; Fisk \& Richardson, 1979; Richman \& Farmer, 1977). Nason (1984a) proposed six criteria for assessing the chlef executive officer's performance:

1. Academic management and leadership.

2. Administrative management and leadership.

3. Budget and finance.

4. Fund raising.

5. External relations.

6. Personal characteristics. (pp. 36-37)

Paxton and Thomas (1977) proposed that an acceptable set of personal characteristics is essential to presidential leadership, and must be considered when studying the performance of the president (p. 351). Evaluation of the chief executive's individual performance is usually based on leadership and managerial style and personal characteristics. Gilley, Fulmer and Reithlingshoefer's (1986) study on academic excellence and leaders was an example of determining what constitutes desirable characteristics for a president. The use of rating scales for chief executive evaluations is a typical methodology for assessing individual characteristics and style. Management by objective formats assess individual performance. 
The two institutional criteria, which appear most often in the literature on chief executive officer evaluations, are planning and change. The outcome of planning, "an operational institutional goal system and related priorities are essential for a useful evaluation of both presidential and institutional success" (Richman \& Farmer, 1977, p. 109). Burns (1978) tied planning to change:

Planning for structural change, whether of the system or in the system, is the ultimate moral test of decision-making leadership inspired by certain goals and values and intent on achieving real social change; it is also the leader's most potent weapon (p. 419). The real test for leaders is whether they have brought about real, intended change by their decisions (Burns, p. 415). The ability to bring about change and innovation in an organization was cited as an indicator for evaluating the chief executive (Bennis, 1976; Peters \& Waterman, 1982; Williams, 1977a). Evaluation methods used to tie chief executive officer performance with institutional performance are long-range planning and goal setting, annual reports, and modifications of management by objective systems.

Determination of criteria. There was general agreement that the criteria for evaluating the chief executive should be set prior to the evaluation occurring (Dick, 1978; Hanley, 1975; McCorkle \& Archibald, 1982; Millett, 1980; Nason, 1984a). In addition, several authors 
recommended that the criteria used for selecting the chief executive officer be the evaluation criteria as well (Astin \& Scherrei, 1980; Fisk \& Richardson, 1979; Munitz, 1980; Williams, 1977a).

Both Tucker \& Mautz (1979) and Cohen \& March (1986) disagreed with the practice of setting evaluation criteria prior to the occurrence of the evaluation. Prior criteria selection assumes the tasks of the chief executive officer remain constant over time and they limit the discovery of new criteria. Kauffman (1980) noted that prior selection of criteria does not happen and further suggested that there are usually no clear criteria given for successful chief executive performance (p. 98). Dick (1978) also noted that criteria not set in advance will lead to more informal chief executive evaluation procedures (p. 11). Informal and Formal Evaluations Another emphasis in the literature on the chief executive officer's evaluation by the governing board centers around the issue of formal and informal evaluations.

Informal evaluation. The informal evaluation of the chief executive officer is more frequent, conducted by the board as a whole, or by an executive of the board. There may be input from other groups through a casual and unsystematic process, such as rumors and general impressions. Because the board may be unfamiliar with the chief executive's activities beyond the board room, informal channels and independent sources may be used for 
feedback on the chief executive's performance (Wood, 1984, p. 41). Informal evaluation is private and confidential, no one other than the board and chief executive knows what occurs. Casual evaluation, observations and communication, can also be considered informal; however, boards just think they are evaluating in this mode (Nason, 1984a, p. 13). The main advantages of an informal chief executive officer evaluation process, found in the literature, were that the governing board remains in control and takes full responsibility for the process and final decisions, a better working relationship between chief executive and board, a strengthening of the chief executive's position and leadership ability and the process remains confidential to protect the chief executive (Beaudoin, 1986; J. L. Fisher \& Quehl, 1984; Hubert, 1986; Kauffman, 1978; Kerr, 1984; Nason, 1984a; Schafer, 1980; Volhontseff, 1987). Formal evaluation. The formal evaluation is less frequent, scheduled at regular intervals and based on objective versus subjective evidence where an effort is made to obtain factual data. Formal evaluation usually includes formal input from other campus related groups and the results of the evaluation may be reported publicly. (Nason, 1984a, p. 14)

Attention was given in the literature to the practices of the board being open to input from others for the evaluation of the chief executive, which was viewed as a natural sequence of shared governance (Arden, 1984, p. 72). Seitz (1980) was concerned that this practice lead to using 
perceptions of subordinates, who were affected by the chief executives decisions, for evaluation. "The aim should be to include only those most qualified to assess. The inclusion of all significant constituencies is considered important since a president's performance may be uneven. . . . [but] Careful consideration should be given to who should give input on what aspects of the evaluation" (Fisk \& Richardson, 1979, p. 349).

Faculty are usually one constituency that provides input to the evaluation of the chief executive. Beaudoin (1986) found that no faculty wanted to evaluate a chief executive to show support. Kerr and Gade (1986) indicated that faculty members almost universally discount the performance of their current presidents at a rate of $25 \%$ to 75\% below that of other observers and cautioned that trustees need to be aware of this discount (p. 44). They provided the reasons why faculty are so hard on president's in evaluation:

1. Faculty members see only a small part of a president's total performance.

2. What they see mostly relates to themselves and to their immediate departments.

3. Their expectations of support for themselves and for their departments often exceed what is possible within the overall constraints within which the institution operates, and within the necessity for elementary fairness in the 
comparative treatment of individuals and departments.

4. Faculty attitudes often are viscerally antiadministration or at least not proadministration. (p. 46)

A typical practice for receiving input is through anonymous questionnaires, which is a controversial practice (Arden, 1984). Kauffman (1980) stated that individuals should not be allowed to volunteer negative statements anonymously. In reference to constituency participation, Cashin (1984) reminded, "we need to distinguish between those who evaluate and those who provide the information or data which serves as the basis for that evaluation" (p. 38). Also, trustees need not permit one group to have more influential input over another (Beaudoin, 1986).

Both informal and formal evaluation can have structure (Wheat, 1981) and may include written policies and procedures.

The main advantages of a formal chief executive officer evaluation, found in the literature, were selection of prior criteria, opportunity for the chief executive to emphasize the complexities of academic leadership and how they have been addressed, open discussion and decisionmaking by the chief executive and the board on management problems, a fair process for the chief executive and a useful gauge of the chief executive's performance for contract renewal and reappointment (Anderson, 1979; 
Beaudoin, 1986; Evans, Mears, \& Wattenbarger, 1979;

Henderson, 1976; Munitz, 1980, 1978).

The four main examples of formal evaluation policies cited were the state Colleges of Pennsylvania, State University of New York, state University System of Florida (Kauffman, 1980) and Minnesota State University System (Hays, 1976). All four states have sunshine laws requiring open or public evaluation procedures (Cleveland, 1985). Cleveland warned, "if you want to have an adversarial situation, conduct a presidential evaluation in public; but if you really want to use evaluations to improve job performance, you can't do it in the public eye" (p. 25).

The formats of chief executive officer evaluations follow the purposes intended by the governing board for the evaluation. The chief executive officer is evaluated on both individual and institutional criteria whether the criteria is set prior to the evaluation or evolves during the process. Chief executive evaluations are conducted using either informal or formal procedures with advantages and disadvantages for both the chief executive and the governing board for each procedure.

\section{Summary}

The explanations and descriptions found in the literature review on the conditions found in a postsecondary institution: organizational setting, chief executive officer and governing board roles, purposes of chief executive evaluation and the form and content of 
evaluations coupled with the myriad of opinions on how these conditions influence the evaluation of the chief executive produced no agreement on what is the best or most effective way to evaluate the chief executive officer. The evaluation of the chief executive officer by the governing board is a multipurpose, multifaceted, complex and situational process which depends on the organizational conditions and the individuals involved at the time of the evaluation.

The Evaluation of the Community College Chief Executive officer

The literature review on the evaluation of the community college chief executive officer focuses on the conditions which make the community college chief executive officer's evaluation different from the evaluations of all postsecondary institution chief executive officers reviewed in the previous section of this chapter. Also, emphasis is placed on the California community college chief executive officer.

\section{Organizational Setting}

Two factors, according to Vaughan (1985), which have contributed to placing community colleges in a management rather than a governance stance are:

1. A movement toward statewide systems of community colleges and the resulting controls and bureaucratic red tape where coordinating bodies and legislatures have more influence on 
curricular decisions than do the local college faculty.

2. An increase in the number of colleges with collective bargaining, which does not fit well into either the collegial or hierarchical model. (p. 17)

Vaughan stated, "today, most community colleges' governance structure is neither clearly hierarchical nor based on shared authority" (p. 17). The hierarchical model comes from the community colleges relationship with the public schools structure and the shared authority comes from the higher education model. Later Vaughan concluded, community colleges have "successfully married the bureaucratic structure with participatory governance" (1986, p. 3). Kerr and Gade (1986) further described the governance structure that results from collective bargaining called "oppositional axis" (p. 128). This structure has two oppositional forces with the board in the middle: one force is the president to the board; the other, the faculty union to the board; and the president and union in conflict for power. Kerr and Gade described the governance model: This oppositional axis arrangement is not uncommon in some community colleges, where faculties are organized into unions with confrontational postures and where the local union movement has significant impact on the appointment or election of board members. President and union business agents exercise dual authority with shifting dominance over each other (p. 128). 
Added to this mixed governance structure is an environment where change is the constant. The turnover rate for both chief executive officers and governing board members is very high. Kerr and Gade (1986) reported a 13\% annual turnover rate of community college presidents nationwide (p. 170) and 17\% in California (p. 172). According to Volhontseff ( 1987) the California community college chief executive's average length of service is 5.71 years (p. 129); and 16 of the 70 districts or $22.9 \%$ changed chief executive officers between 1985 and 1986 (p. 1). Vaughan (1986) reported that $15 \%$ to $20 \%$ of the community college trustees are new to the position each year (p. 55). Also, governing boards are becoming more political with California community colleges being cited as an example (Gleazer, 1985, p. 45).

\section{Roles of the Chief Executive officer}

and the Governing Board

Even though Vaughan, in 1983, described the community colleges as becoming more managerial, his study of community college presidents concluded that the president's most important role was that of leader who is responsible for these functions:

1. establishing and interpreting the mission of the college;

2. managing the environment;

3. maintaining institutional vitality; and

4. articulating the college's mission to external constituent groups. (p. 55) 
Gleazer (1985) expressed concern, however, that the relationship between the community college boards and their chief executive officers was impacting the leadership style of the chief executive:

Obviously, marked differences exist among institutions, but precipitous firings, short terms of office, and public displays of disagreement are numerous enough to arouse concern. Contributing to board-president tensions are such factors as diversity in board membership, political and special interests, and the complexity of the problems to be dealt with. Trustees often charge that they are being spoonfed and are not getting the information they need to make responsible judgment, while presidents contend that they are not evaluated professionally (p. 48). Key to a good chief executive-board relationship is the joint leadership role of the governing board chairperson and the chief executive. Popock (1984) stated, "the single greatest contribution to be made to the president by the [governing board] chairperson is to lead and manage the board well" (p. 3). Typically, in California community colleges, the board chairperson position rotates annually, which may make stable board leadership difficult. Hubert (1986) confirmed in his study that many presidents do not enjoy a trusting relationship with their boards, particularly in the California community colleges (p. 158). 
Both Potter (1979) and Gleazer (1985) agreed that the governing board is responsible for evaluating the chief executive officer. Potter observed, though, that many boards have opened up the evaluation process to other segments of the campus and added a periodic self assessment by the chief executive (p. 55). Gleazer (1985) suggested, "it would be better to conceive of the board's responsibilities as appointing the president, supporting the president, and monitoring the president's performance" (p. 48) than the traditional responsibilities of hiring and firing the president, which is a less supportive board role.

\section{Form and content of the Chief Executive Officer's Evaluation}

The review of the literature produced no special patterns or models for the form and content of community college chief executive officers' evaluations by governing boards.

Vaughan (1986) concluded from his study that community college chief executive officers should be evaluated on institutional criteria:

Since the success of a leader is ultimately judged on the success of the enterprise he or she leads, the success of the community college president must ultimately rest on the ability of the college to achieve its mission, a mission that is committed to providing educational opportunity to a board-based constituency (p. 103) 
Hubert (1986) found in his study of California college and university presidents, not chief executive officers, that the majority of the community college presidents were evaluated informally (p. 107). He found a reluctance on the part of the community college governing boards to use formal evaluations and that the presidents serving such boards did not force more formal procedures on them ( $p$. 153)

Volhontseff (1987) found in her study on the California community college board-chief executive officer partnership and evaluation that informal practices enhance the board-chief executive relationship, but do not provide the chief executive with clear expectations against which performance is measured (p. 94). Also, she found that since there was no overall correlation between informal and formal evaluation and the chief executive's image and behavior, the data did not contribute to the support of either type of evaluation (p. 95).

\section{Summary}

The conditions that influence the evaluation of community college chief executive officers by governing boards are dual governance structures within the same institutions, politicized boards, collective bargaining, and high turnover of both chief executives and board members which effect the chief executive officer and governing board relationship. These same conditions exist in the California community colleges, and in some cases, with greater intensity. 
Summary of the Review of the Literature

Central to this study on the evaluation of California community college chief executive officers by governing boards is the determination of what constitutes an effective evaluation, one which improves the chief executive officer's performance from the perception of the chief executive. The review of the literature presented the theoretical foundations of evaluations of people in organizational settings and in postsecondary institutions as well as the opinions of experts, board members and chief executives officers on the purposes and the form and content of postsecondary institution chief executive officer evaluations, yet no definitive answers on the effectiveness of the evaluations were found. Kerr and Gade's (1986) opinion on the ideal chief executive officer evaluation is given as a summary:

To be fair, evaluation must look at both performance in all areas and over the total period served; and it must be sensitive to the role of fate as well as to self-chosen actions. Memories of past accomplishments often have been too short and impressions of recent problems too deep. The central question should be: Has the person, overall, done the best possible job for the time and the place? It is also helpful if the president is told in advance what he or she is expected to accomplish and how the review of accomplishments will be conducted. If reviews are 
public (and preferably they should not be), they should be conducted against previously stated and specific tests of performance and in accord with precise and known methods of evaluation. Advice about how performance is perceived should always long precede the actual review so that corrections can be undertaken in advance. Preferably evaluation should be made of the president, of other top administrators and the board--all together (pp. 179-180). 
Chapter III

RESEARCH DESIGN AND METHODOLOGY

Research Design

To examine the district governing board evaluations of California community college chief executive officers, an ethnographic research design and qualitative methodology were used. Both Beaudoin (1986) and Hubert (1986) used ethnography in their study of presidential evaluations. Ethnography means learning from people rather than studying people (Spradley, 1979).

Ethnographies are analytic descriptions or reconstructions of intact cultural scenes and groups. - . They recreate shared beliefs, practices, artifacts, both knowledge and behaviors of some group of people. . . Studies can focus on a single setting or a common phenomenon over several settings (Goetz \& Lecompte, 1984, p. 2-3).

Kirk \& Miller (1986) defined qualitative methods as follows:

Qualitative methods is a procedure for counting to one. Deciding what to count as a unit of analysis is fundamentally an interpretative issue requiring judgment and choice. This choice cuts to the core of 
qualitative methods--where meanings rather than

frequencies assume paramount significance.

Qualitative work is blatantly interpretative (p. 5).

Goetz \& Lecompte (1984) suggested using these five

conventions in an ethnographic research design:

1. The place of the theory in the research: The theories develop as the phenomena are studied, instead of proposing hypotheses to be tested.

2. Selecting and sampling: Informal selection is used, not probability sampling to search for comparability and translatability of the data.

3. Preconceptions and postconceptions: The researcher must recognize subjectivity and avoid observer bias.

4. Accommodation and manipulation: The phenomena are studied as they occur or occurred versus manipulating in advance.

5. Trianqulating and converging: Data is cross checked to prevent accepting initial impressions to enhance scope density and clarity of constructs.

The term trianqulation means to combine methods of data sources (interviews, documents, observation) or accounts of events to make comparisons of some phenomena. Both Fielding \& Fielding (1986) and Hammersley \& Atkinson (1984) emphasized the importance of triangulation in ethnographic research design.

What is involved in triangulation is not the combination of different kinds of data per se, but 
rather an attempt to relate different sorts of data in such a way as to counteract various possible threats to the validity of our analysis (Hammersley \& Atkinson, 1984, p. 199) .

The researcher engaged the Goetz \& Lecompte conventions in conducting the research for this study.

Site Selection and Sample

The procedures used for selecting the sites and sample for this study were quasi qualitative to insure representation of the perceptions of the 70 California community college chief executive officers on the effectiveness of their evaluations by district governing boards. From the 70 California community college districts, the following 20 districts were selected as sites for this study:

Butte

Foothil1-DeAnza

Imperial

Marin

Miracosta

San Diego

Santa Barbara

sierra Joint

State Center

West Kern citrus

Fremont-Newark

Lake Tahoe

Merced

Rancho Santiago

San Luis obispo County

Santa Monica

Sonoma county

Ventura county

Yosemite 


\section{Site selection}

Site selection requires that the researcher delineate precisely the relevant population or phenomenon for investigation using criteria based on theoretical or conceptual considerations, personal curiosity, and empirical characteristics (Goetz \& LeCompte, 1984). Three characteristics of the 70 California community college districts were used to select the sample sites: (a) multicollege and campus district or single college district organization, (b) northern or southern California location of the district, (c) the district's chief executive officer's length of service as the superintendent.

The first two characteristics are common distinctions in California community college literature. The third characteristic was defined as a five year length of service based on the assumption that a chief executive officer with an initial four year contract should have received at least a one year contract renewal; and therefore, should have been evaluated to be able to respond on the effectiveness of his or her evaluation by the district governing board. The California Education Code of 1983, Vol. 3, Title III, Div. 7, Section 72411 permits a four year term of service for the superintendent; thus, a fifth year becomes an extension or renewal of the initial contract. The California community college districts were then divided into two groups: Group one--districts with a chief executive officer who as of November 1987 had been in the position five years or more; and Group two--districts with a 
chief executive officer who as of November 1987 had not been in the position for at least five years or districts who had interim chief executive officers as of November 1987. As of November 1987, there were 29 districts which met the characteristics of group one.

The selection of sites was based on information gathered from the chief Executive officers of California Community Colleges Directory (1987), the California Association of Community Colleges Directory (1987), and personal telephone calls by the researcher to community college district offices.

The Sample

The sample for this study consisted of the 20 California community college chief executive officers from the 20 selected districts. The sample participants were fifteen district chief executive officers from group one and five district chief executive officers who had been in the position for two years from the remaining 41 districts in group two. The sample was composed of the two groups of chief executive officers to incorporate the recommended complementary strategies of Glaser \& Strauss (1967): minimize the differences between cases to highlight basic properties of a particular category; and then subsequently maximize the differences between cases to increase the density of the properties relating to core categories, to integrate categories and delimit the scope of the phenomena (pp 44-45). 
A stratified random selection was used for selecting sample participants from both groups to insure that each group represented California's proportions of multi-college and multi-campus to single college districts and northern and southern California district locations.

The 20 selected chief executive officers were sent a letter requesting an interview from the researcher, Appendix A, along with a letter of support for the study from the researcher's chief executive officer, Appendix B. Nineteen chief executive officers from the initial sample accepted the interview invitation. To replace the one chief executive officer who was unable to participate, random replacement from the same group which represented similar district characteristics of the non-participating chief executive officer was used. The replacement accepted the interview invitation.

\section{Data Collection}

Interviews, documents and participant observation were the data collection procedures used for this study. It is difficult to make a clear demarcation between collecting and analyzing data in ethnographic research because the design evolves or emerges as the study evolves and the researcher is the instrument (Lecompte \& Goetz, 1984). As the data was collected, it was analyzed.

\section{Interviews}

The interview technique was used as the primary method to gather data for this study. Volhontseff (1987), based on 
her survey instrument methodology to study the evaluations of California community college chief executive officers, recommended the interview process. She found that both the chief executive officer and the board members were very candid when she met face to face with the study participants to validate her findings. Many ethnographers would agree that direct experience is the most reliable form of knowledge about the social world, but all social research does not have to be direct experience. The ethnographic methods of investigative interviewing and participant observations, therefore, can be used to approach direct experience (Douglas, 1976).

The unstructured interview method is the most used in ethnographic research. Experts assume that this is a better method for assessing the goals, intentions, purposes and behavior of another. (Brenner, Brown \& Canter, 1985; Hammersley \& Atkinson, 1984; Schwartz \& Jacobs, 1979). However, Patton (1980) stated that the major weakness of the unstructured interview is that "different information [is] collected from different people with different questions. - . [It is] less systematic and comprehensive if certain questions don't arise 'naturally.' Data organization and analysis can be quite difficult" (p. 206). The interviews for this study were both structured and unstructured in form.

Patton (1980) suggested using several types of questions in the interview: experience/behavior, opinion/value, feeling, knowledge, sensory, and 
background/demographic. Also, he stressed the importance of the timeframe and sequence of questions; and that questions should be asked presuming the person has something to say.

The key to a successful ethnographic interview is asking descriptive questions that encourage the interviewee to talk about a particular cultural scene (Spradley, 1979). The interviewing of chief executive officers falls within the realm of Dexter's (1970) elite interview method. Elite interviewing stresses the interviewee's definition of the situation, encourages the interviewee to structure the account of the situation, and lets the interviewee, to a great extent, determine what is relevant (Dexter, 1970, p. 5). The researcher used these interviewing and questioning techniques in this study.

\section{Pilot Study}

The researcher conducted three practice interviews with three retired community college chief executive officers living in the San Diego area. These interviews were taped and coded to refine the interview questions and techniques.

\section{Interview Procedure}

The structured questions based on the review of the literature and the pilot study that were used for the interviews are found in Appendix $C$. The researcher completed the 20 interviews during the period of January 27 through March 4, 1988. The length of interviews varied from one to three hours with the average length of $11 / 2$ 
hours. The interviews were recorded by tape, after permission was gained from the interviewee, and by brief field notes. The tapes were transcribed and combined with the field notes for coding.

\section{Documents}

Documents are secondary sources of data for ethnographers, but they are useful and should be used where appropriate in the research. Documents are considered either formal or informal. The official board adopted evaluation policies and procedures of the 20 districts were the formal documents used for this study. Evaluation memorandums, letters, news articles, etc. that the chief executive officers shared with the researcher provided the informal documentation.

official documents and social statistics should be treated as a social product rather than a source of data. They must be examined, not simply used as a resource. To treat them as a resource and not a topic is to trade on the interpretative and interactional work that went into their production. They should be treated as a reflection or documentation of the work phenomena that are actually produced by it. Informal documents must be viewed from the teller's perspective. (Hammersley \& Atkinson, 1984).

\section{Observation}

"Interviews must be viewed as social events in which the interviewer is a participant observer. . . . All interviewing accounts must be examined as a social phenomena occurring in, and shaped by, a particular 
context" (Hammersley \& Atkinson, 1984, p. 126). The interviews and observations occurred together in this study to verify the data since the line between the two methods is a very fine one.

Nineteen of the 20 interviews were conducted in the personal offices of the chief executive officers to insure a natural and comfortable interview setting for the interviewee and to permit observation by the researcher to occur. One interview was conducted by telephone per the request of the interviewee due to scheduling conflicts.

\section{Confidentiality}

The Human Subjects Committee of the University of San Diego using the expedited review process approved the proposal for meeting the standards of confidentiality. The interviewees were assured that their responses would be reported anonymously and each interviewee signed the Informed Consent Form, Appendix D.

\section{Data Analysis}

Data analysis consists of the process of rereading, scanning, determining categories, assembling parts of data and writing down thoughts to condense the data into a meaningful form. Mostyn (1985) and Goetz \& Lecompte (1984) summarized the analytic process as making inferences and then integrating and interpretating the data, going beyond description and treating words as symbols and data with attributes of their own. The constant comparison method of Glaser \& Strauss (1967) was used in this study. This 
method combines inductive category coding with a simultaneous comparison of all social incidents observed, which is a continuous process throughout the research. The goal is to delimit the categories to define and describe the theory, trends, and themes that exist for the phenomena being studied.

Immersion in a particular culture still remains one of the most proven methods for finding themes (Spradley, 1979). In writing the ethnography the researcher searched for the relationships or themes within the California chief executive officers evaluation practices and procedures by governing boards to answer the research questions of this study .

\section{Limitations of the Research Methodology}

The strength of ethnographic design is its internal and external validity due to the richness of the data, non simultaneity of treatment across persons, multiple sites, times and persons (Kidder, 1981; LeCompte \& Goetz, 1984).

A limitation of ethnogrpahic design is its reliability because replicating the reporting of natural occurrences is very difficult. To control for threats to the reliability of the study, the researcher needs to specify precisely the research design and methods and the ethnographic decisionmaking which occurs during interviewing (Kirk \& Miller, 1986). The 20 interviews in the study were self-reporting of a phenomena and therefore can be challenged on the basis 
of truthfulness and the inability to replicate the findings.

To reduce the threat of the generalizability of the study, the researcher insured that statewide characteristics of the 70 districts were represented in the sample of chief executive officers interviewed. It was recognized that the generalizability of the study results to community college chief executive officers outside of California is limited.

Another potential limitation to the study was the bias of interviewing only chief executive officers who have a contract with a district. 


\title{
Chapter IV \\ ANALYSIS OF THE DATA
}

\begin{abstract}
Introduction
The sample for this study consisted of 20 California community college districts and their chief executive officers. They were selected from the 70 California community college districts based on three characteristics, described in chapter III of this study: (a) multi-college and multi-campus district or single college district organization, (b) northern or southern California location of the district, and (c) the district's chief executive officer's length of service as the superintendent.

The chief executive officers were interviewed using ethnographic methodology to collect data on their perceptions of their evaluations by their governing boards. The analysis of the data for this study is organized into three sections to answer the three research questions on governing board evaluations of 20 selected California community college chief executive officers. The chapter sections are: (1) present governing board policies and practices for evaluating chief executive officers; (2) effective chief executive officer evaluation policies and
\end{abstract}


practices, as perceived by the chief executives; and (3) factors_which effect chief executive officers' evaluations and contribute to effective evaluations, as perceived by the chief executives.

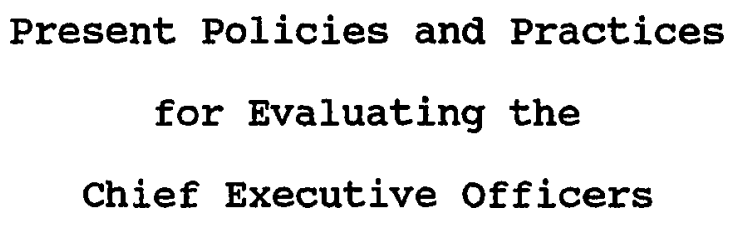

The descriptions of the present governing boards' evaluation policies and practices of the 20 California community college chief executive officers boards were analyzed by the form and content of the evaluations which provided the answer to Research question No. 1 of this study: "What are the present policies and practices being used by the 20 selected California community college district governing boards to evaluate their chief executive officers?"

Form of the Chief Executive Officers' Evaluations

The form of the 20 California community college chief executives officers' evaluations was analyzed by the written and unwritten policies and practices and the formats of the chief executive officers' evaluations. Annual and Unwritten Evaluation Policies and Practices

Eight of the 20 chief executive officers had written district evaluation policies, 12 of the 20 did not; however, four of the 12 had clauses in their contracts stipulating that an evaluation would occur. Nine of the 20 
chief executive officers had written evaluation procedures and practices, and 11 of the 20 did not.

sixteen of the 20 chief executive officers were evaluated annually with three of the 16 reporting a variation of up to six months had occurred in the past. One of the 20 was evaluated every two years; one of the 20 , every three years; and two of the 20 were evaluated on no regular basis. Fifteen of the 20 chief executive officers indicated that they were evaluated by their boards on an ongoing basis as well.

It was found that the majority of the 20 chief executive officers have no written policies (the four contracts were not considered district policy) or practices by which their governing boards evaluated them; however, the majority were evaluated on an annual basis.

Initiation of the policy or practice. The responses to the interview question, "Who initiated or developed your present evaluation policy?" (the 'policy' was also interpreted to mean practice by the responding chief executives) produced these results: the chief executive officer developed the policy, 8; the governing board, 5; the chief executive officer and governing board jointly, 2 ; and the chief executive officer's predecessor, 5 . The responses to the question, "Who takes the initiative to start the evaluation process?" produced these results: Tied to dates of contract renewal and/or salary adjustment, 11; scheduled by policy, 6; and the chief executive officer, 3 . 
It was found that the chief executive officers played a major role in the initiation and development of their evaluation policy or practices. Also, the majority of the districts had determined a set time for the evaluation of their chief executive officers.

Formats of the Chief Executive officers' Evaluations

Table 1 summarizes the frequency of formats used by the 20 chief executive officers. The majority of the chief executive officers had evaluations that combined more than one format with the combination of open discussion with the board and one other format being the most prevalent. The other combination that emerged as a possible pattern was an evaluation that used the combination of self-evaluation and goal setting and/or planning formats. The most commonly used evaluation formats among all 20 chief executive officers were goal setting and/or planning, self-evaluation and written instrument formats. Also, the majority of the chief executive officers indicated that they were evaluated on an on-going basis which had no format at all.

The significant trends that evolved from the analysis of the chief executive officers' evaluation formats were the use of combination formats and the on-going basis format.

\section{Chief executive officer style and format of the}

evaluation. An analysis was made of the relationship of the chief executives officers' self-described styles in working with their boards and the format of the governing boards' evaluation of the chief executives. The styles analyzed were: (a) sending written communications 
Table 1

Frequency on Formats of Chief Executive Officers' Evaluations

Number of

Chief Executive officers

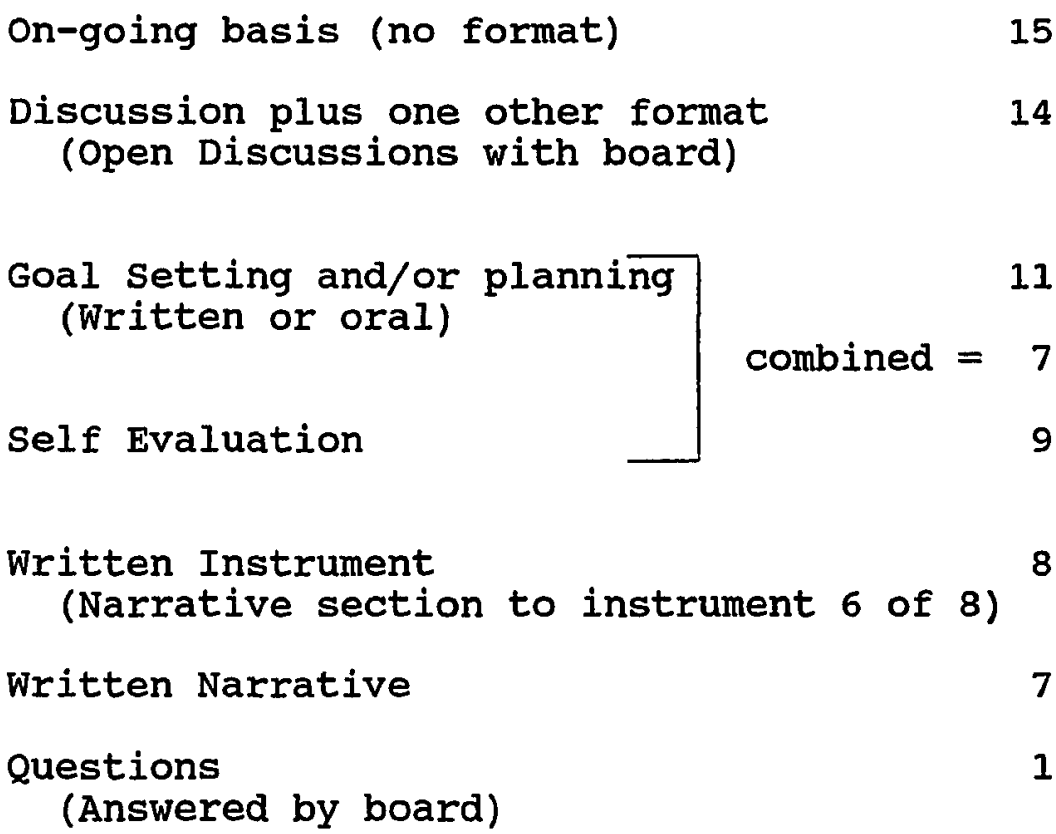

aseveral of the Chief Executive Officers' Evaluations were combinations of one or more formats.

(memorandums, bulletins, topical updates) to the board other than those required such as agendas, policies and legal documents; (b) working with board members individually; (c) working with the board as a group usually through the chair; (d) using a combination of individual and group working relationships; and (e) using board committees. The evaluation formats analyzed were: (a) the use of written policies and practices, instruments and open exchange discussions; (b) individual or total board feedback methods; and (c) the chief executive officer's presence during the 
evaluation. This analysis produced no significant patterns. Settings of the Chief Executive Officers' Evaluation

\section{Meetings}

Table 2 summarizes the 20 chief executive officers' descriptions of the settings for their evaluations by the governing boards, and the major findings based on frequency of occurrence were:

1. All 20 chief executives' evaluations occurred in an executive session board meeting as prescribed by California Education Code on personnel actions.

2. Fourteen of the 20 chief executive officers' evaluation meetings occurred either before, after or during the entire regularly or specially scheduled governing board meeting.

3. Thirteen of the 20 chief executive officers and their boards had an open exchange discussion during the evaluation.

4. Thirteen of the 20 chief executive officers provided their boards with goals and objectives and/or selfevaluations in either written or oral form during the evaluation meeting.

Two settings that were not significant based on frequency of occurences appeared to be important because they were self reported as significant by the chief executives officers:

1. Eleven of the 20 chief executives officers were present during the entire evaluation session. 
Table 2

Settings of Chief Executive Officers' Evaluation Meetings

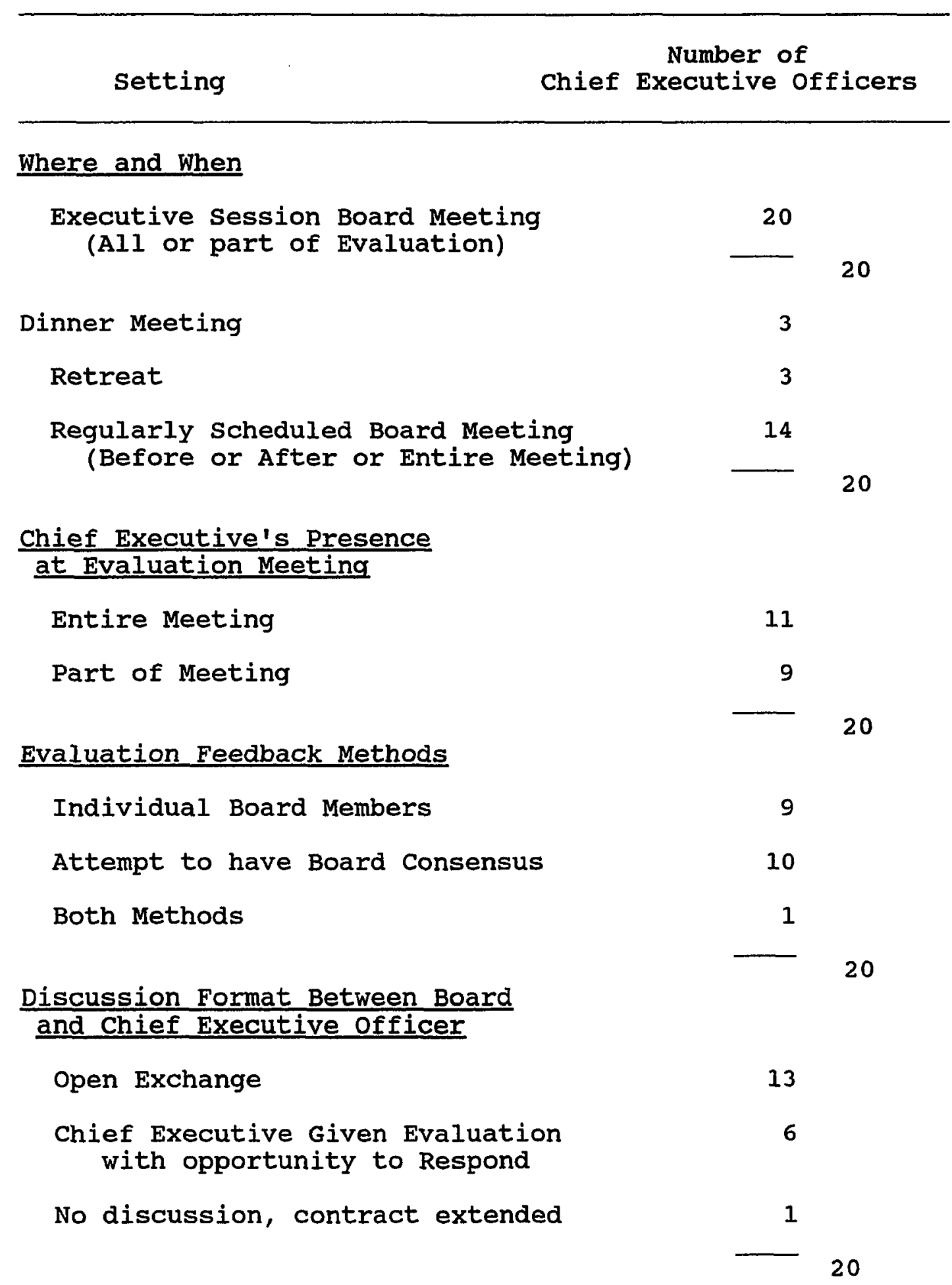




\section{Format Settings}

Instrument Used:

Chief Executive/Board Complete

Separately and Compare

1

Board only completes

Written or oral statement by

Chief Executive officer Used:

Goals/objectives and/or

Self Evaluation given to Board

Planning Advisory Committee Feedback

13

Feedback on Board's Performance

Given by Chief Executive officer

Results of Evaluation Placed in Chief Executive's Personnel File
8

1

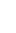

3

4

aNo-Total due to combination of formats

2. Ten of the 20 chief executive officers were given feedback on their performance in a meeting where the board members attempted to reach consensus, nine chief executives received individual board member feedback, and one chief executive had experienced both kinds of feedback methods.

In summary, the majority of the chief executives were evaluated annually and at a predetermined time using no written policies or procedures, played a significant role in the initiation and development of their evaluation policies and practices, and were evaluated in similar settings with combination formats and the on-going basis format based on the analysis of the data on the form of the governing boards' evaluations of the 20 California community college chief executive officers. 
Content of the Chief Executive Officer's Evaluations

The content of the 20 California community college chief executive officers' evaluations was described and analyzed by the feedback channels used by the board to evaluate the chief executive officers, the purposes and criteria for evaluating the chief executive officers and the formal and informal evaluations of the chief executive officers.

Feedback Channels Used by the Governing Board

The responses to several interview questions on the practices and procedures the board used to receive feedback for the chief executive officers' evaluation were used to analyze the governing boards' feedback channels. All of the 20 chief executive officers indicated that the board was ultimately responsible for evaluating them and no one else. Sixteen of the 20 governing boards used no structured process or feedback channel to receive input from other people or groups on the performance of their chief executive officer. Nineteen of the 20 chief executives indicated that informal feedback channels were used to varying degrees for input to their evaluation. The majority of chief executive officers reported that the faculty and in some cases classified staff used the informal feedback channels.

An analysis of the responses to the interview question, "How much importance is placed on their [the group or persons identified by the chief executive] input by the board?" produced no significant patterns on the impact the 
informal feedback channels used by the board had on the chief executive officers' evaluations. The effect of these informal board feedback channels varied significantly because of the individual boards and individual board members attitudes toward the use of the channels coupled with the format of the chief executives' evaluations. The descriptions of the structured feedback channels used by four of the 20 governing boards were:

1. Surveys or statements by the faculty senate and the classified staff may be given to the governing board as per written procedure; however, the chief executive noted that the process was not always used.

2. A planning advisory committee consisting of administration, faculty and classified staff gave input to the board during an annual day and a half meeting. Part of the process was to evaluate the chief executive's performance in the planning process.

3. An anonymous survey of faculty and classified staff was tabulated and given to the board every two years. This process was for information only, and not part of the written evaluation policy.

4. The faculty senate executive committee wrote a statement on the performance of the chief executive and it was given to the board, but the timing of the submittal did not necessarily coincide with the boards' evaluation of the chief executive.

Also, three of the four chief executive officers with structured board feedback channels indicated that informal 
channels were used also, especially when perceived problems existed or during collective bargaining negotiations.

Chief executive officers' feelings on informal

channels. The responses to the interview question, "How do you feel about their [the group or persons identified by the chief executive] input to your evaluations?" are summarized by statements from the chief executive officers which reflect the majority of the chief executives' feelings on informal feedback channels used by their boards to varying degrees as input to their evaluations:

"They are perceptions, but they may not be the reality." "A lot of evaluative comments are made at one time or another during a year, as they are in most institutions, and I am sure some of that is heard by the board." "When you are talking about the evaluation of the chief executives [using informal channels], $90 \%$ of what those board members are dealing with is your personality and your interpersonal style." "I feel very strongly that I don't work for them [faculty], I work for the board. I think if a person in this role is subject to an evaluation by the people who work for them, it hampers their ability to make difficult decisions." "I don't know how you do it [control informal feedback channels], it is a popularity poll. Particularly when you have collective bargaining, each year you sometimes make an enemy because you have to say 'no' to somebody." "Any faculty criticism would be discounted fairly heavily [by the board]." "Well, the 
informal input I just think, it is a fact of life. You can't do anything about it. So I don't necessarily have strong feelings about it. The biggest concern I would have is that whatever is stated that it would be put out on the table and dealt with." Knowledge of chief executive officers' performance. The interview question, "Who do you feel is the most knowledgeable about your performance as the chief executive officer?" was asked to determine if the chief executives perceived the governing board, who evaluates them, to be the most knowledgeable. It was found that only one of the 20 chief executive officers felt the board was the most knowledgeable about their performance. No pattern was found in the other 19 chief executives' responses in which administrators; administrators, secretaries and assistants; board chairs; faculty senate presidents; faculty; peers; and spouse were named solely or in combinations. The majority of chief executives, however, perceived that they had multifaceted roles which make it difficult for one person or group to evaluate their total performance in their positions. As one chief executive stated, "That is really difficult [the question], there is no one individual or group that sees all facets of my job."

Based on an analysis of the data on governing board feedback channels, it was found that a majority of the governing boards used some form of informal feedback channels for input to their chief executives' evaluation; however, no significant patterns evolved on how these 
channels affected the evaluation or how the chief executive felt about the use of the informal channels. It was determined also that the majority of the chief executive officers perceived their position to be multifaceted; and therefore, felt no one group or person was knowledgeable about their performance in totality. Purposes for Evaluating Chief Executive officers

Responses to the interview question, "What has been the purpose for your board evaluation or what is your evaluation used for by the board?" were categorized by collegial, bureaucratic and political purposes (Baldridge's model as discussed in chapter 2 of this study). The majority of the 20 chief executive officers gave multiple purposes for their governing board evaluations.

Collegial purposes. The chief executive officers described this purpose as evaluation for improvement of performance, open feedback on performance, and open exchange between the chief executive and board. Fourteen of the 20 chief executives officers indicated that there was a collegial purpose for their board evaluations; however the ranking frequency produced these findings: primary or first purpose, 6; second, 5; and third, 3 .

Bureaucratic purposes. The chief executive officers described this purpose as evaluation for contract renewal and salary adjustment, direction from the board on managing the college and a supervisor-employee relationship. Nineteen of the 20 indicated a bureaucratic purpose for their evaluations and eight of the nineteen gave two 
bureaucratic purposes for their evaluations. Thirteen of the 20 gave contract renewal as the primary purpose for their evaluations. As one chief executive commented, "the evaluation leads to one consistent question,'shall the terms of the contract be continued another year.' The evaluation is always tied to that question."

Political purposes. The chief executive officers described this purpose as evaluation by feedback to the board based on perceptions of the constituencies and as a way for the board to vent their frustrations. six of the 20 chief executive officers indicated a political purpose for their evaluation with half of the six indicating it was the secondary purpose of the evaluation. The constituency that four of the six chief executives referred to was the faculty.

one chief executive commented on the reasons for evaluating a chief executive and incorporated all three purposes and the complexity of their affect on the evaluation:

They are political, they are tied to constituency perceptions, and they are tied to promises made in election campaigns and so forth. I think you can't overcome those kinds of things in evaluation. Some people lose their jobs because it is viewed as the only way to solve a problem. It becomes symbolic and evaluation can't change that. So I think the real reason, the fundamental reason for evaluating a superintendent/president is to really go to this 
question of objectives and making course adjustments to bring about a better alignment, or to bring about progress whatever it is. To try to insure that the board and the superintendent are in tune and at least can play the same tune, which I think has always been very critical.

Two significant findings evolved from an analysis of the purposes for governing boards' evaluating their chief executives: (a) the majority of the 20 chief executives perceived the primary purpose for their evaluations to be bureaucratic; and (b) the majority of the 20 chief executives perceived the collegial or the improvement of their performance purpose for their evaluation not to be the primary or secondary purpose. Criteria for Evaluating the Chief Executive officers

An analysis of the responses to the two interview questions, "How do the formal criteria that are used in your evaluation square with what the board members indicate they are concerned with?" and "In the absence of formal criteria, what are the processes and dynamics of your evaluation?" produced findings on the formal and informal criteria being used by the governing boards to evaluate their chief executives officers and the chief executives officers' perceptions on what criteria should be used to evaluate them.

Formal and informal criteria used to evaluate the chief executive officers. Six of the 20 chief executive officers reported that they were evaluated on formal criteria and 
only three of the six chief executives had written evaluation formats or policies. Seven of the 20 chief executive reported that they were evaluated on informal criteria and four of the seven indicated that their relationship with their governing board was the key criteria. And the remaining seven of the 20 chief executives reported that they were evaluated using both formal and informal criteria.

Based on the chief executives' responses, it appeared that the meaning given by the chief executives to the term "formal criteria" was that the criteria used for their evaluation were stated, open and or understood by them and that these criteria did not have to be in writing. The meaning of "informal criteria" appeared to be related to the relationship between the chief executive officer and the governing board which was not necessarily an objective criteria nor stated or open. As one chief executive explained, "No matter how objective you make it [the evaluation], there is a certain amount of subjectivity in evaluation" which was described as the "chemistry between the chief executive officer and the governing board." Another chief executive commented on this informal criteria or relationship with the board:

You can be dead right, you can say, 'I have met all my goals and objectives, I have done everything you have asked me [to do],' and they can say, 'I don't give a damn, I don't like the way you did this.' You can say, 'well, that is not fair,' and they can say, 'fine, 
count the votes.' You have got to please the board whether you like it or not and as much as you spell out in the evaluation, it is only as good as they really feel rather or not you are doing a good job. And this is in the gut and that is informal. And yes, I think every chief executive officer ought to have an evaluation with their board, but I would strongly recommend that they don't rest on that. Criteria which should be used to evaluate chief executive officers. Seventeen of the 20 chief executives felt that they should be evaluated on both institutional and individual criteria or factors which they described as institutional results achieved, changes made, morale or climate of the institutional environment, vision, managing and leadership. Several of the 17 chief executive officers commented that the they should be evaluated on whether they have brought about change or made a difference or improvement in the institution. As one chief executive stated:

We have a system that reinforces low risk behavior. The people who make waves, bring about change and do not win popularity contests are the ones who do the good job. They should be rewarded for it, not punished. The way managers should be evaluated? Ask "have you changed things lately?" The ideal measure on an evaluation instrument should be the measurement of change, because it is such a dynamic system. I fear the most current evaluations are much more 'don't rock 
the boat.' We give very high marks for not upsetting people.

Three of the 20 chief executives felt that they should be evaluated on the individual criteria of ability to communicate and interpersonal skills.

Several chief executives felt the criteria for evaluating the chief executive should not necessarily be pre-determined. One chief executive summarized this perception:

Is the chief executive officer able to manage the institution for the time in which it happens to be imbedded at the time the evaluation is done? In other words, is the chief executive officer on top of the current situation whatever that happens to be. An institution cannot be static and the chief executive officer must take advantage of the opportunities when they occur.

Fifteen of the 20 chief executive officers indicated that the criteria used by the governing boards to evaluate them correlated directly with the criteria they perceived should be used for their evaluations. An analysis of the evaluation criteria responses was made to determine if experience as chief executive officers changed the chief executives' perceptions of the criteria which should be used to evaluate them and no relationship was found.

Based on the analysis of the criteria data, it was found that the majority of the chief executive officers are evaluated using both formal and informal criteria and the 
informal criteria were related to the chief executive and the governing board relationship which may be more subjective. In addition, a majority of the chief executives felt that they were evaluated on the criteria they perceived they should be evaluated be on by their governing boards.

Formal and Informal Chief Executive officer Evaluations

An analysis was made to determine whether the 20 chief executive officers were evaluated formally or informally because the literature review for this study found several references categorizing chief executive officers' evaluation by governing boards as either formal or informal in format. Nason's (1984a, p. 14) description of a formal evaluation was an evaluation which is less frequent, regularly scheduled, based on objective evidence and usually includes formal input from other campus related groups and the results of the evaluation may be reported publicly. In analyzing the form and content of the 20 chief executive officers' evaluations, it was found that no chief executive's evaluation met the formal evaluation description because their evaluations lacked formal input from the campus groups and the results of their evaluations were not made public. Twelve of the 20 chief executive officers, interestingly still described their evaluations by the governing boards as being formal. It appeared that the chief executive officers generally perceive a formal evaluation as an evaluation which is scheduled regularly and usually annually, is in some written evaluation format 
and is considered formal when contrasted to their informal, on-going evaluation format (or no format).

In response to the interview question, "Is your board under pressure to evaluate you in a more formal, public way than they do now?" 18 of the 20 chief executive officers stated their board was under no pressure to evaluate them more formally. Only two of the 20 chief executives indicated that their governing boards had been under some pressure over the last few years to provide for formal faculty input on the chief executive officers' performance. Five of the 20 chief executives described their evaluations as being informal and three of the 20 described their evaluations as being casual.

A significant finding based on the data on formal and informal evaluations was that over half of the chief executives perceived their evaluations to be formal even though no formal input from other constituencies was a part of their evaluation. Also, no trend existed for the chief executive officers' evaluations to become more formal.

The interview question, "Has the content and form of your evaluation changed over the length of your service in this position?" was asked to determine if a pattern existed for changing a chief executive officer's evaluation because they had gained experience in the position. Thirteen of the 20 chief executive officers indicated no change had occurred. Of the seven of the 20 chief executives reporting a change, four indicated that change was to a written format evaluation. 
In summary, the majority of the governing boards used, according to their chief executives, some form of informal feedback channels with no patterns apparent on how the input affected the chief executive officers' evaluations, bureaucratic purposes as the main purpose for their chief executives' evaluations, criteria which were considered appropriate and formal evaluation practices based on the data analysis of the content of the 20 California community college chief executive officers' evaluations.

\section{Effective California Community College Chief Executive officers' Evaluation Policies and Practices}

The description and analysis of the effective governing board evaluation policies and practices of the 20 California community college chief executive officers provided the answer to Research Question No. 2 of this study: "Which California community college chief executive officer evaluation policies and practices, of the 20 selected districts, are perceived by the chief executive officers to effectively improve their performance?" The data analyzed for this research question was the governing boards' role in the evaluations, the chief executive officers' perceptions on the relationship of their governing board evaluations and improvement of their performance, and the policies and practices identified by the chief executive officer's as effective. 


\section{Governing Boards' Role in Evaluation}

The responses from two interview questions were used to analyze the governing boards' role in the evaluations and whether the 20 chief executive officers perceived their governing boards' evaluations to be fair.

\section{Governing Boards' Role as Evaluators}

In response to the question, "Do you feel the board is comfortable in their role as your evaluator?" 15 of the 20 chief executives answered yes, and two of the 15 indicated that their comfortableness with the role had evolved over time. One chief executive commented, "I think they take the job very seriously and they recognize that the performance in this role strongly influences the effectiveness of the college and its progress." Some other reasons for the board feeling comfortable in the role as evaluator, quoting different chief executives, were:

"They hire and fire the chief executive officer." "Yes, but they don't evaluate me on the serious things." "It gives them power." "Their role is not active." "Some relish it!"

Five of the 20 chief executives felt that their boards were not comfortable in evaluating them because board members had no experience in evaluation, did not like to do it, were embarrassed by it, and found it stressful (although the chief executive indicated that was appropriate because it resulted in honest feedback). One chief executive suggested this reason for the board's uncomfortableness in evaluating, "They are pleased with the 
way things are going, maybe some of them don't want to hear anything negative."

The majority of the chief executives felt that their board was comfortable in evaluating them; however, no themes were found on the reasons the chief executives perceived the boards were comfortable in their roles as evaluators.

Fairness of the Governing Boards' Evaluations

In responding to the question, "Do you feel your evaluation policy or board evaluation practices have been fair?" 17 of the 20 chief executives responded yes, some with qualifiers. Some of the reasons for responding yes, quoting the chief executives, were:

"Fair because I know what is required." "Open and frank." "Not related to salary and not necessarily related to contract renewal." "Experienced board." "Renewed my contract."

Some of the reasons with qualifiers were:

"Performance of the board uneven at times, not all sessions helpful." "one board member not fair, solicited comments that were used in the evaluation." "Such as it was, yes."

Three of the 20 chief executives officers perceived their evaluation policies and practices to be unfair because an open exchange had not occurred. They felt isolated by the design of the process, and their evaluation did not motivate them to perform better. 
The majority of the chief executive officers perceived their governing boards' evaluation policies and practices to be fair, but no pattern on their perceptions was apparent.

In summary, the majority of the 20 chief executive officers perceived their boards to be comfortable in evaluating them and their evaluations to be fair; however, no patterns were evident on the explanations for the chief executive officers' perceptions.

\section{Chief Executive Officers' Evaluations}

and Improvement of Performance

The 20 chief executive officers' perceptions on the relationship between their governing board evaluation and the improvement of their performance were analyzed by using the responses from four interview questions.

\section{Evaluation Should Change Behavior}

Based on the responses to the interview question, "Do you feel your board evaluation is really suppose to change your behavior or actions?" it was found that five of the 20 chief executives felt that their governing board evaluations should change their behavior; and, 13 of the 20 indicated their evaluations should change their behavior or actions but added some limitations. Eight of the 13 indicated they would not change to a behavior or action that was counter to their basic philosophy or value system because of the governing boards' evaluations. Some statements, quoting the chief executives, expressed the sentiments of the eight: 
"I don't think it can change, for example, philosophically how you view community college administration, or how you operate." "The board happens to be my employer. However, I am professional to the profession itself. And if the board were to tell me to do something that is totally against my value system and what it good for community colleges, I would be looking for another job." "They have a perfect right to tell their district chief executive officer what their expectations are of his or her behavior. Now if I don't like that I don't have to stay here. But as long as I am here, as far as I am concerned I have the duty to try to do the job according their standard."

Five of the 13 chief executives indicated that behavior should be changed as an outcome of evaluation, but that the change did not usually occur because of an annual evaluation, instead the on-going format was more likely to result in behavioral change. One chief executive explained:

It [evaluation] is suppose to [change behavior], we all think that it is suppose to, but I don't think that it does in the short run. It occurs very, very slowly. I don't think the formal annual does it as much as the immediate feedback. Or, as another chief executive stated, "evaluation is an on-going, continuous process and that modifies my behavior." 
Two of the 20 chief executives stated that their evaluation should not change their behavior. Evaluation Changed Behavior

The responses to the interview question, "Do you feel your evaluation by the board has really changed your behavior or actions?" produced a "yes" from 18 of the 20 chief executive officers with eight of the 18 indicating that the change occurred as part of an on-going response to the governing boards' concerns. As one chief executive explained:

The chief executive officer is pulled in four different directions: board, faculty/staff, community and official bureaucracy [State]; and he or she needs to earn a passing grade in all four and so your job is a balancing act. I guess if I am going to compromise, it is not going to be against the board.

Two of the 20 chief executives indicated that they had not changed their behavior or actions because of their evaluation by their board.

Chief Executive officers' Knowledge of their Performance

The responses to the interview question, "Has there ever been a doubt in your mind where you stand with the board relative your job performance?" produced 11 definite "no" answers; 6 "no" answers with the board as a whole, but not with individual members; and 3 "yes" answers because there had been one or two times while they were in the position when they were not sure where they stood with the board on their performance. 
Specificity of Governing Boards' Evaluation Suggestions

Based on the responses to the interview question, "As a result of your evaluation, how specific are the board's suggestions for improving your performance?" it was determined that for 7 of the 20 chief executives the suggestions were more specific in nature; 5, more general; and 8 , both general and specific. Several chief executives commented that the suggestions were on direction to take versus an improvement in performance. Some statements of the chief executives that explained the differing perceptions on the boards suggestions:

"Evaluation is a refining process." "specific, but it is hard at times to sort out what the real specific concern is." "We work hard at keeping them general." "Very specific as the result of the [evaluation] instrument, more general when they are verbal." "Not helpful in the management of the college and its functions, but helpful reminders that board must be given appreciable amounts of time."

The significant findings based on the data analysis of the chief executive officers' perceptions on the relationship between their governing boards' evaluations and the improvement of their performance were that the majority of the chief executives felt their evaluation should change their behavior or actions and, in fact, they had changed their behavior or actions because of their evaluations. Also, the majority of the chief executive officers knew where they stood with their boards on their performance, but 
no consistent theme evolved on whether their knowledge was the result of specific or general suggestions from the governing boards.

\section{Chief Executive officer Identified}

\section{Effective Policies and Practices}

Two interview questions were used to determine effective governing board evaluation policies and practices which the 20 chief executives perceived as improving their performance.

\section{Effective Policies}

The responses to the interview question, "If you could start now, what type of evaluation policy would you develop and why do you think it would be effective?" determined that 14 of the 20 chief executive officers would not develop new policies because they considered their present policy to be effective.

From the previous analysis in this chapter on the form and content of the 20 chief executive officers' evaluation polices and practices, there was no evidence to suggest a policy existed which was considered effective by any significant number of the 20 chief executive officers. A possible explanation for the lack of identification of any one type of policy was suggested by eight of the 20 chief executives: the governing board's evaluation of the chief executive officer should fit the environment of the district or institution. It was determined previously in this chapter that external and internal environments of the 20 districts were so varied and complex that it would be 
reasonable to assume one chief executive evaluation policy could not fit all 20 environments.

of the six of the 20 chief executive officers who would change or modify their present policies to make them more effective, five of six would change the policy by giving it more structure through defined criteria, stated expectations, goals or objectives, or tying it to a planning process.

\section{Effective Practices}

The responses to the interview question, "What components or elements of your evaluation have been the most effective in improving or affecting your performance?" produced no similarities on effective practices. The frequency of responses (some chief executives identified more than one practice) for the chief executive officers identified effective governing board evaluation practices were: 8 of the 20 chief executives, the open communication with the board during the evaluation; 8 of the 20 , a written and/or an instrument component to the evaluation; 7 of the 20 , the direction and/or goals and objectives the chief executive received agreement on during the evaluation; 6 of the 20, the evaluation was an on-going process; and 4 of the 20, the evaluation occurred regularly.

The majority of the 20 chief executive officers identified their policy to be effective for improving their performance, but no themes evolved on what was considered an effective policy because of the possible variables of differing district environments; and no similarities existed 
on effective governing board practices for evaluating chief executive officers.

\section{Chief Executive officer Identified \\ Evaluation Factors Contributing to \\ Effective Evaluations}

The description and analysis of the sample of the 20 California community college districts and their chief executive officers resulted in several factors being identified as having an effect on the chief executive officers' evaluations. These factors are organized on by: (a) the organizational settings of the districts, (b) the chief executive officers of the districts, and (c) the governing boards of the districts.

The description and analysis of the 20 California community college chief executive officers' perceptions on the effective evaluation factors which contribute to improving the chief executive's performance provided the answer to Research Question No. 3 of this study: "What factors contribute to effective evaluations by improving the performance of California community college chief executive officers as perceived the chief executive officer?"

\section{Factors Affecting}

\section{Chief Executive Officers' Evaluations}

Several factors were identified as having an influence on the chief executive officers' evaluations, however, the 
effect did not necessarily result in the governing boards' evaluation being effective.

District organizational settings

Based on the research design, the districts in the sample were located equally between northern and southern California and five of the sample districts had multicollege or multi-campus district organization. Nineteen of the 70 California community colleges are multi-college or campus district organization, which represents $27.1 \%$ of all districts statewide and $5.42(.271 \times 20=5.42)$ of the 20 districts in the sample. Whether a district had a single college organization or not was indicated to be significant by six of the 15 single college district chief executive officers. The significance was in the different role expectations of the chief executive officer. The single college chief executive must deal directly with both community and the on-campus constituencies, mainly the faculty, on a daily basis; and these chief executives believed that the multi-college or multi-campus district chief executives have a "cushion" between them and the faculty. Four of these six chief executive officers believed that being in a single college district had an influence on their evaluation because of faculty relations. The student body size of the sample districts ranged from 40,151 to 1,384 with ten of the districts falling in the range of 5,000 to 15,000 students. Table 3 summarizes the sample districts' student body size. It was found that 
Table 3

Sample Districts' student Body Sizea

\begin{tabular}{cc}
$\begin{array}{c}\text { Number } \\
\text { of Students }\end{array}$ & $\begin{array}{c}\text { Number } \\
\text { Districts }\end{array}$ \\
\hline $40,000+$ & 1 \\
$35,000-39,999$ & 1 \\
$30,000-34,999$ & 0 \\
$25,000-29,999$ & 2 \\
$20,000-24,999$ & 1 \\
$15,000-19,999$ & 2 \\
$10,000-14,999$ & 3 \\
$5,000-9,999$ & $\mathrm{~N}=$ \\
$1,000-4,999$ & 20 \\
\hline
\end{tabular}

a Fall 1986 Headcount from California Association of Community Colleges. (1987). CACC Directory. Sacramento, CA: Author.

the size of a district's student body was not significant in relation to the chief executive officer's evaluation by the governing board.

External environments of the districts. All 20 districts experienced the same external environments that were a result of their relationship to the california state Governor, Legislature, Community College Chancellor's office, and the Education Code; however, the different geographical location of each district resulted in each district having a different community environment. Each chief executive officer was asked the question, "Are there 
any unique characteristics about your district which affect your evaluation? What are they and how has the board responded to them?" Six of the 20 chief executive officers indicated that the district environment had not affected their evaluation and gave these descriptions of their external environments: (a) one was a microcosm of a large city with $50 \%$ ethnic background, (b) one was diverse ethnically and politically, and spread out geographically; and (c) four were small towns. Fourteen of the 20 chief executive officers who described their communities similarly indicated that their district characteristics did influence their evaluations. Six of the 14 chief executives had small town environments and described them as political, conservative, ultraconservative, ethnically diverse, individualistic, or isolated. The other eight of the 14 chief executive officers used such descriptions for their suburban and urban districts as political, diverse, multi ethnic, middle class, wealthy, affluent and professional. An analysis of these external district descriptions compared to the effect on the chief executive officers' evaluation produced no similarities.

Based on the data, it appeared that in the majority of the 20 districts, the chief executive officers believed that the external environment or community did have some impact on the expectations of the district's community college governing board. A general but not consistent pattern was found by matching the community and the expectation produced for the chief executive officer's 
performance. For example, communities described as political generally resulted in the political expectations that the chief executives respond to the constituencies, but in two instances that was not the expectation, which suggests other factors such as the internal environment, the roles of both the chief executive and the governing board may modify the influence of the external environment.

Internal environments of the districts. Baldridge's (1971) campus governance model of collegial, bureaucratic and political structures was used to determine if a relationship existed between the type of internal governance structure and the influence on the chief executive's evaluation by the governing board. The governance structures and the descriptions of the effect or the expectation by the governing board for the chief executive officer's evaluation used to analyze the data were: collegial, chief executive is expected to be a part of the professional community where open exchange occurs; bureaucratic, chief executive is expected to manage the people, finances and environment of the institution; and political, the chief executive is expected to respond to the constituencies.

Table 4 summarizes the governance structures of the 20 districts as described by the chief executive officers and the resulting effects on their evaluations by the governing boards. Eighteen of the 20 districts had collective bargaining. Negotiations and collective bargaining are considered a political governance activity (Baldridge, 
Table 4

Governance Structures and Evaluation Effects

\begin{tabular}{|c|c|c|c|c|}
\hline $\begin{array}{c}\text { District Governance } \\
\text { structuresa }\end{array}$ & of & $\begin{array}{l}\text { Number } \\
\text { Districts }\end{array}$ & & $\begin{array}{c}\text { Effect } \\
\text { on Evaluations }\end{array}$ \\
\hline $\begin{array}{l}\text { Collegial } \\
\text { Collegial/ } \\
\text { Political }\end{array}$ & & 1 & $=$ & collegial \\
\hline Bureaucratic & & 1 & & \\
\hline $\begin{array}{l}\text { Bureaucratic/ } \\
\text { Political }\end{array}$ & & 7 & $=$ & Bureaucratic \\
\hline $\begin{array}{l}\text { Political/ } \\
\text { Bureaucratic }\end{array}$ & & 5 & & \\
\hline Political & & 4 & $=$ & Political \\
\hline
\end{tabular}

aFirst governance structure of two structures listed is the more prominent in practice.

1971). The existence of collective bargaining resulted in political structures for the districts; and in 14 districts caused multiple governance structures. In those districts with multiple governance structures, one structure was prominent over the other in that they were not equal structures in practice.

of the two districts without collective bargaining, one district was collegial and the other bureaucratic. For the three districts with a collegial structure, the effect on the evaluation tended to be a collegial one: two chief executive officers had very informal and open, free flow discussion format evaluations; the third chief executive 
had a bureaucratic format evaluation (a detailed form and procedure), which was used to structure an open discussion occurring in a collegial atmosphere.

In the 12 districts with varying degrees of both bureaucratic and political governance structures, the bureaucratic structure usually modified the political environment for the evaluation of the chief executive officer. In the four districts with only political structures, the effect was that the evaluation tended to have more political overtures.

It was found that in the districts where there had been very turbulent times (dismissal of the previous chief executive officer and/or extreme financial problems and/or morale problems) prior to the chief executives taking the positions, the governing boards hired the chief executive officers to correct the situation which resulted in more bureaucratic governance structures and bureaucratic format evaluations.

Several chief executives mentioned that district tradition or "the way it has always been done" attitude produced the same evaluation practices for all of the district's chief executive officers, suggesting that a district's history may modify other factors that influence the practices for evaluating a chief executive officer.

Based on the analysis of the data from the 20 districts, it was found that the multiple variables in a district's internal environment coupled with its unique external environment were perceived by the chief executive 
officers as having an influence on the governing board's evaluation of its chief executive officer, but the degree of the effect was unique to each district which then becomes significant for that district only. District Chief Executive Officers

The profile of the 20 California community college chief executive officers highlighted their number of years as the 20 districts' chief executives and as community college administrators, type and length of their contracts with the districts, use of a job description as part of their evaluations and their self-description of their roles as chief executives officers.

Chief executive officers' years of experience. Five of the chief executives interviewed were in their present position less than five years and 15, more than five years. Table 5 summarizes the distribution of the 20 chief executive officers' number of years as the districts' chief executives. The sample mean number of years in the position was 8.35 and the median, 9. The design of the study produced a sample with more years of experience in the same position as a chief executive officer than the statewide average of 5.71 years (Volhontseff, 1987, p. 129) . 
Table 5

Years of Experience as District Chief Executive officer

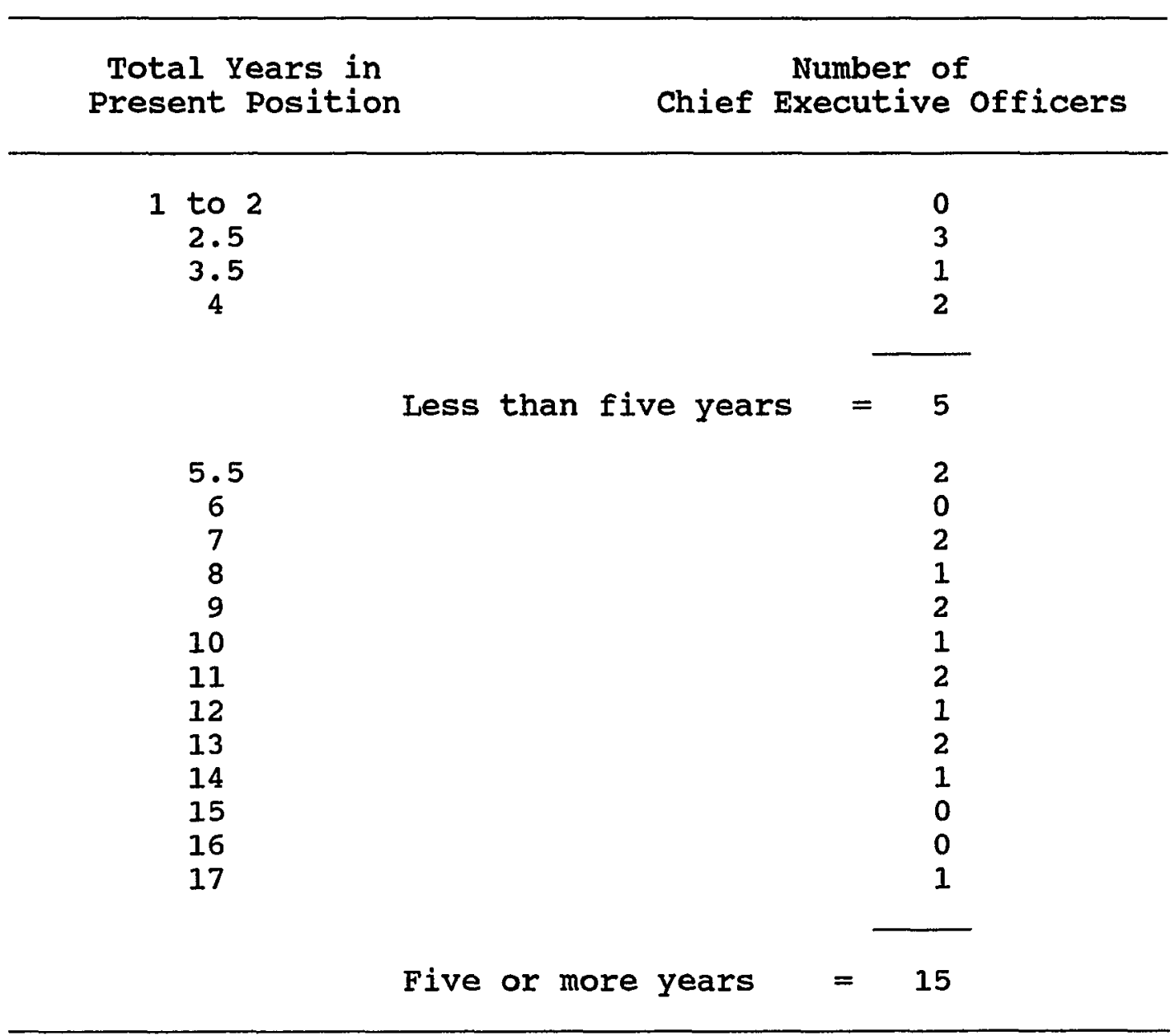

Mean $=8.35$ years $;$ Median $=9$ years

Table 6 summarizes the distribution of the 20 chief executive officers' number of years as community college administrators. The research design produced a group of experienced community college administrators with a sample mean number of years of 21.85 and a median, 20 . of the 20 chief executive officers, six indicated that they had been chief executive officers prior to their present position. The general consensus of the six was that their previous evaluation policies and practices were not appropriate for their new position because of the 
Table 6

Chief Executive Officers' Years of Experience

as community college Administrators

\begin{tabular}{cc}
$\begin{array}{c}\text { Total Years } \\
\text { of Experience }\end{array}$ & $\begin{array}{c}\text { Number of } \\
\text { Chief Executive Officers }\end{array}$ \\
\hline $1-12$ & 0 \\
$13-14$ & 3 \\
$15-16$ & 1 \\
$17-18$ & 1 \\
$19-20$ & 5 \\
$21-22$ & 2 \\
$23-24$ & 3 \\
$25-26$ & 1 \\
$27-28$ & 2 \\
$29-34$ & 0 \\
$35-36$ & 2 \\
\hline
\end{tabular}

Mean $=21.85$ years $;$ Median $=20$ years

differences in both the internal and external environments of their previous institutions; therefore, they were being evaluated using different evaluation policies and practices or modifications of their previous ones.

Chief executive officers' contracts with districts. Table 7 outlines the type and length of contract each of the 20 chief executive officers had with their districts. California Education Code permits a community college governing board to have up to a maximum of a four year contract with its chief executive officer. Eighteen of the 20 chief executive officers had four year contracts with their districts. Nine of the 18 were straight four year contracts with renewal occurring prior to expiration; and two of these contracts were renewed two to three years prior 
Table 7

Type and Length of Chief Executive officers' contracts

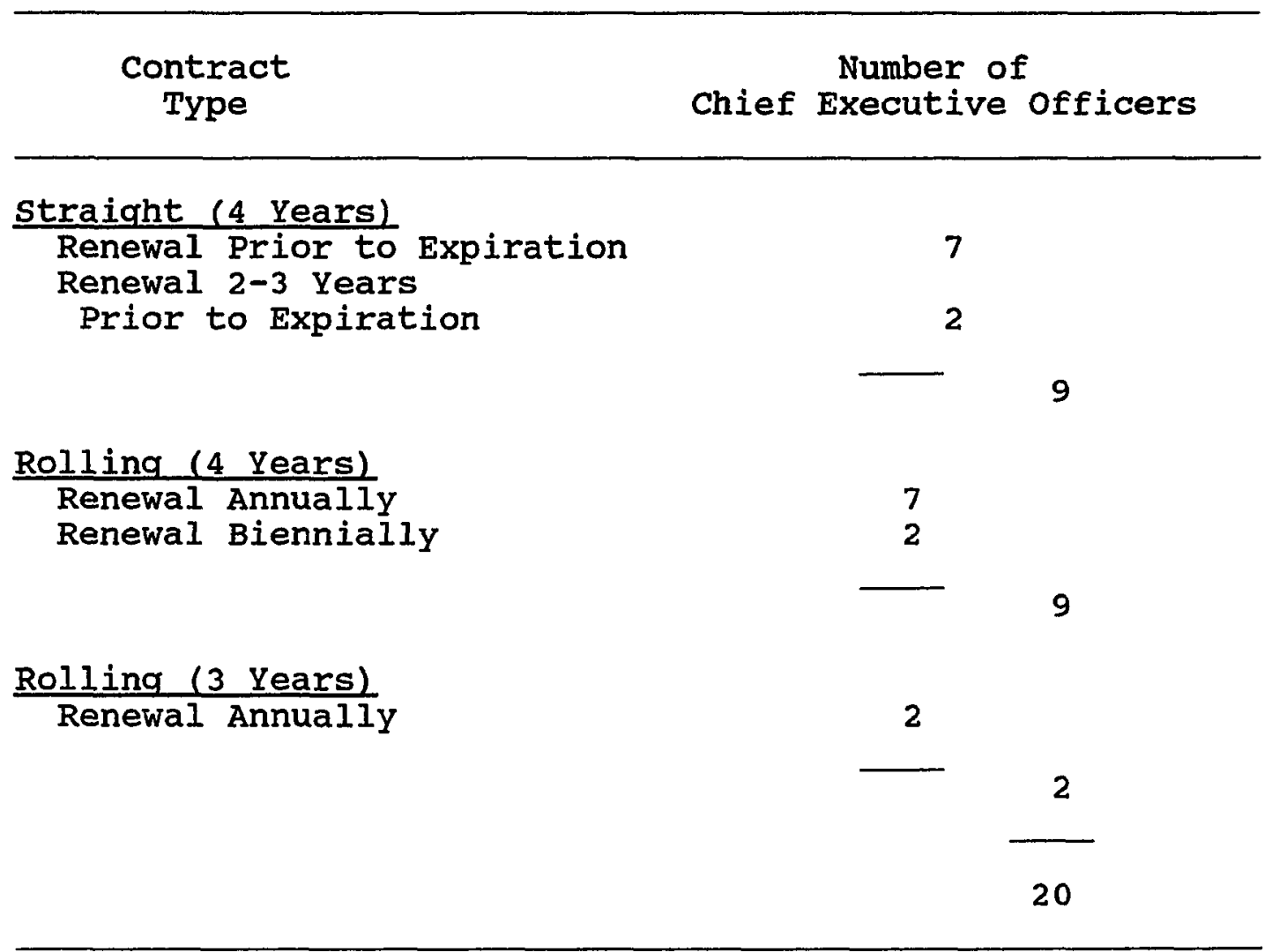

to expiration. The other nine were "rolling" contracts with either annual or biennial extensions. A rolling contract means that an extension is added on to the end of the contract with the chief executive maintaining a full length contract. Two of the 20 had three year rolling contracts with annual renewals. Sixteen of the 20 chief executive officers indicated that contract renewal was a part of their evaluation by the governing board, but the type and length of the contract was not perceived significant by the chief executive officers in relation to their evaluations. 
Chief executive officers' job descriptions. The responses of the 20 chief executive officers to the question, "How does your job description relate to your evaluation?" produced these results:

1. Eighteen out of 20 had written job descriptions, 2 did not.

2. Eight of the 18 indicated there was a correlation between their job description and their evaluation by the governing board either in the design of the evaluation instrument, criteria used for the evaluation or discussion on performance with the governing board.

3. Two of the eight indicated revision of their job description had occurred as a result of their evaluation.

4. Twelve of the 20 chief executive officers or the majority indicated that their job description was not a significant part of their evaluation by the governing board.

Chief executive officer roles. Table 8 depicts the prominent roles the 20 chief executives officers felt that they had in their positions. Thirteen of the 20 chief executives indicated dual roles which they said occurred because of their differing relationships with the community, the governing board and the district faculty and staff. An analysis was made of the chief executive officers' self-described roles compared to the to the criteria they perceived should be used to evaluate their performance. Five of the 20 chief executive officers were not evaluated on those criteria or factors that they 
Table 8

Self-Described Chief Executive officer Roles Chief Executive officer
Rolesa

Manager/Leader

Leader/Manager

Managerso

Political/Manager

Political Leader

Communicator/Statesperson
Number of Chief Executive officers
3

5

7

1

3

1

20

aRole listed first in dual roles was emphasized more by Chief Executive officer. oThe Manager role was also referred to as Administrator role by 3 Chief Executive officers.

perceived should be the criteria; and three of the remaining 15 chief executive officers hedged on their "yes" answer that the criteria actually used for their evaluation was what they perceived should be the criteria.

It was found that the chief executive officer's selfdescribed roles and the criteria actually used for evaluation may have a greater influence on the outcome of the chief executive officer's evaluation when the roles and criteria used are not congruent. For example, if the chief executive officer perceives her or his role as a political leader and the board is using management criteria, the evaluation results would have a negative outcome. 
Based on the analysis of the profiles of the 20 chief executive officers, it was found that the chief executive officers' years of experience as a community college chief executive and administrator and their job descriptions did not have a significant influence on the chief executive officers' evaluations. It was found, however, that the chief executives' self-described roles in relation to their perceptions of the criteria that should be used to evaluate them may be significant, especially when they are not congruent.

District Governing Boards

The profile of the 20 California community college district governing boards highlighted their size of membership and changes of membership during the tenure of the chief executive officers, the board chair positions and the chief executive officers' descriptions of their governing boards.

Governing boards' membership. Of the 20 districts, 13 districts had seven member boards and 7 districts had five member boards. Table 9 summarizes the number of changes in board members each chief executive officer had experienced during his or her tenure by size of board membership. Three board membership changes during the chief executive's tenure was the modal condition whether the board had five or seven members. The chief executive officers perceived that the number of changes became more significant in relation to their evaluation depending upon how the change occurred, not necessarily that there had been changes. 
Table 9

Board Member Changes During Tenure of Chief Executive officer

Number of Changes

in Board Members

Frequency of

Changes

Five Member Board

$\begin{array}{ll}\text { One } & 2 \\ \text { Two } & 2 \\ \text { Three } & 5 \\ \text { Four } & 2 \\ \text { Five } & 0\end{array}$

Seven Member Board

Zero 1

One 2

Two 1

Three 3

Four 0

Five 1

Six 0

Seven 1

Board member changes that were a result of appointments were not as significant as board changes due to elections. Three chief executive officers mentioned the phenomena of elections with faculty-backed candidates, which in some cases made the relationship between the chief executive officer and the board strained at times. One chief executive commented, "I think in all candor, it [the evaluation] depends on the changes that can occur in a board. A satisfactory evaluation can become an unsatisfactory one with the same person doing the same job. There is a political aspect or dimension to this [evaluation]. And it can be used in that way." 
Board chair position. All 20 districts had the practice of rotating the chair position among the board members with 17 districts experiencing changes every year and the remaining three districts experiencing changes every one or two years depending upon other variables outside of standard practices for the district. Several chief executive officers commented on the relationship between the chief executive and the board chair, as one chief executive explained, "the chair can affect how your year goes which is due to the uneven abilities of some of the board members." The role the board chair played varied among the 20 districts. Some chair positions were considered perfunctory because the chief executive worked with the board mainly on an individual basis, some chair positions were powerful and had the ability to change the format of the chief executive officer's evaluation or had the responsibility to administer the evaluation procedures. As one chief executive commented, "If you have a stable board, changing chairs may not matter, but if it [the board] is unstable it doesn't work."

The uneven abilities of some board chairs coupled with the responsibilities they have in the evaluation of chief executive officer were significant for only those chief executive officers who experienced those situations.

Descriptions of the governing boards' stability. The chief executive officers used the term "stability" to describe several conditions: how well the board worked together, how well the board worked with the chief 
executive in both group and individual modes, how the board responded to constituencies (Iistening and making sound decisions or just reacting) and the degree of support the board gave the chief executive.

Sixteen of the 20 chief executive officers described their governing boards as stable to very stable and two of these 16 boards were described as unstable in the past. Three of the 20 boards were described as being unstable and one of the 20 boards was described as relatively stable and improving.

An analysis was made to determine if chief executive officer described board stability had an affect on the evaluation of the chief executive officer, and no patterns were found to suggest that unstable boards always produce negative or positive effects on the chief executive's evaluation; and interestingly, stable boards did not always produce positive effects on the practices for evaluating chief executive officers.

An analysis was also made to determine if chief executive officer described unstable boards were considered political boards (how they responded to the constituencies, especially using informal channels) by the chief executive officer, and that proved true for the three unstable boards, but six of chief executive officers of stable boards also described their boards as being political. For all nine boards that were described as political and either stable or unstable, no theme was found on how these conditions affected the chief executives' evaluations. 
Based on the profiles of the 20 governing boards, it was found that changes in board membership and board chair positions varied in degrees of significance on the effect of chief executive officer's evaluations; the influence appeared to be related to the ability of individual board members and the motives for being a board member; and for the board chair, the amount of power and status of the position. Chief executive officers' descriptions of their boards' stability and political behavior produced no significant relationship between the descriptions and the effect on the chief executives' evaluations by their boards.

\section{Evaluation Factors Identified as}

Contributing to Effective

\section{Chief Executive Officer Evaluations}

Analyzing the responses to the interview question, "What do you feel is the most important factor in assessing the performance of a chief executive officer?" and comparing them to the answers given by the 20 chief executive officers on effective policies and practices resulted in the identification of two factors that the majority of the 20 chief executive officers perceived to contribute to their improved performance. The factors identified were the relationship between the governing board and the chief executive officer and the governing board's written or unwritten expectations and/or goals and objectives for the chief executive officer. 
Relationship between the Chief Executive officer and and the Governing Board

Fourteen of the 20 chief executive officers indicated that the relationship between the governing board and the chief executive officers was a major factor that contributed to their improved performance. Words used by the chief executives to describe this relationship were trust, honesty, open, and supportive. The importance of the relationship for the evaluation, according to the chief executive officers, was that it provided for open communication, exchange and feedback between the chief executive officer and the governing board; a relationship with no hidden agendas. Several chief executives mentioned the importance of maintaining their relationship with their board and that it was an on-going relationship, not necessarily tied just to their annual evaluation. Two chief executives explained their methods for maintaining this relationship; one had four rules:

1. Never ever disrespect your board.

2. Remember even the least adept board member can occasionally have a good idea; don't randomly discount a board member based on your past experience.

3. Never lie to your board.

4. Use finesse in how you bring them the bad news. Another chief executive advised that the foundation for a good governing board relationship was built on providing the board information so that they were never surprised, by 
being patient, and by listening carefully to the boards' expressed needs.

Governing Board's Expectations for the Chief Executive Officer

Thirteen of the 20 chief executive officers indicated that a major factor which contributed to improving their performance was that the governing boards' expectations and/or goals and objectives were known by the chief executives. According to several of the chief executives, this factor had some relationship to a planning process that they participated in with the governing board as a part of their evaluation. The governing boards' expectations and/or goals and objectives did not have to be in a written form, but they had to have been discussed and agreed upon by both the board and the chief executive. In several cases, the evaluation session consisted of both the chief executive and the board evaluating how well the chief executive performed the goals and objectives during the year and then determining the goals and objectives for the next year.

Eight of the 14 chief executives who identified the relationship factor also identified the board expectations factor. Two chief executives' descriptions of their evaluation process summarized the majority of chief executive officers' perceptions on the two effective evaluation factors which contributed to their improved performance. Quoting one chief executive: 
I think the chemistry between the board and the chief executive officer is so critical that any evaluation process should be worked out between the two. So that the agenda for the evaluation, the purposes of the evaluation, and the expectations or results of the evaluation are open with everybody up front.

And, the other chief executive stated:

I think it is essential that you have one [an evaluation]. I think the process is more important than the evaluation. First it is that relationship of the chief executive officer and the board, that honesty. So the evaluation is important, but the process of forcing that relationship, knowing that you are going to look at each other; looking at the college goals, how they get set; and how they reflect in my goals is the most important. From the data analysis on the evaluation factors contributing to effective governing board evaluations by the governing boards, the significant findings were that the majority of the chief executives identified the factors of the relationship between the chief executive and the governing board and the chief executive's understanding of the governing boards' expectations as contributing to their improved performance. It was found also that a general pattern existed among fourteen of the chief executive officers that these two factors were both important to their evaluations. 
Summary of the Data Analysis

This chapter presented the analysis of the data collected from interviews of 20 selected california chief executive officers on their governing board evaluation policies and practices.

The present governing boards' policies and practices for evaluating their chief executive officers were described using the form and content of the evaluations, and then analyzed to determine if any general patterns existed and the major findings were:

1. The majority of the chief executive officers were evaluated annually and at a predetermined time using no written policies or procedures.

2. The majority of the chief executive officers played a significant role in the development of their evaluation policies and practices and they were evaluated in similar settings with combination formats and the on-going basis format which was no format.

3. The majority of the governing boards used some form of informal feedback channels for input to the evaluations from various constituencies with no patterns of effect evident on the chief executives' evaluations.

4. The majority of the governing boards used bureaucratic purposes as the main purpose for evaluating their chief executive officers.

5. The majority of the chief executive officers considered their evaluation criteria to be appropriate and their evaluation practices to be formal. 
The governing boards' evaluation policies and practices were described and analyzed to determine those which, from the perceptions of the chief executive officers, had effectively improved their performance and the major findings were:

1. The majority of the chief executive officers perceived their boards to be comfortable in their role as evaluator and their governing boards' evaluations to be fair.

2. The chief executive officers perceived their evaluation policies to be effective because their evaluations improved their performance, but no trends were evident on what was considered an effective policy.

3. No general patterns existed among the governing board evaluation practices which were identified as effective by the chief executive officers.

The sample was described and then analyzed to determine the impact the factors of the districts' organizational settings, the district chief executive officers and the governing boards had on the governing boards' evaluations of their chief executives and the major findings were:

1. Both the internal and external district environments have an influence on the chief executive officers' evaluations, but the degree of the effect is unique to each district.

2. The chief executive officers' years of experience in their positions, the type and length of their contract 
and their job descriptions have no significant impact on their evaluations.

3. The chief executives' self-described roles in relation to their perceptions of the criteria which should be used to evaluate them may be significant when the roles and criteria used are not congruent.

4. Changes in governing board membership and board chair positions may have an effect on the chief executive officers' evaluations depending on the individual board members.

5. The chief executive officers' descriptions of their boards' stability and political behavior indicated no significant relationship between those factors and their impact on the chief executive's evaluation.

The majority of the chief executive officer identified two evaluation factors which contributed most often to their effective evaluations and to their improved performance:

1. The relationship between the chief executive officer and the governing board.

2. The chief executive's understanding of the governing board's expectations and/or goals and objectives.

These findings formed the basis for the conclusions and recommendations of this study presented in chapter $V$. 
CHAPTER V

SUMMARY, CONCLUSIONS AND RECOMMENDATIONS

Summary of the study

The governing board of a California community college district is responsible for the evaluation of its chief executive officer, and how this responsibility is carried out is at the discretion of the governing board. As a result, chief executive officers are evaluated by their governing boards in variety of ways, using multiple criteria and purposes, and with varying degrees of formality. According to C. F. Fisher (1978), the intent of a chief executive officer evaluation by the governing board is to help the chief executive improve his or her performance (p. 7).

The focus of this study was to examine whether the California community college chief executive officers perceived their governing boards' evaluation policies and practices to be effective, and whether those evaluations contributed to their improved performance. An ethnographic research design and methodology were used for this study and 20 selected California community college chief executive officers were interviewed. Three research questions were posed and answered by this study to determine if the chief 
executive officers perceived their governing board evaluations to be effective:

1. What are the present policies and practices being used by the 20 selected California community college district governing boards to evaluate their chief executive officers?

2. Which California community college chief executive officer evaluation policies and practices, of the 20 selected districts, are perceived by the chief executive officers to effectively improve their performance?

3. What factors contribute to effective evaluations by improving the performance of California community college chief executive officers, as perceived by the chief executive officer?

\section{Conclusions of the study}

The conclusions of this study are based on the findings from interviewing 20 selected California community college chief executive officers on their perceptions of their governing board evaluations. This chapter section is organized by the three research questions and the conclusions for each one.

\section{Research Question No. 1}

Research Question No. 1 of the study was: "What are the present policies and practices being used by the 20 selected California community college district governing boards to evaluate their chief executive officers?" 
Policies and Practices

Both Kauffman (1980) and Fisk and Richardson (1979) suggested that the college chief executive officers take an active role in the initiation of their evaluation policies and practices. The literature review produced no consensus on what constitutes the appropriate form and content for a chief executive officer evaluation by the governing board, but the use of multiple or combination formats for chief executive officer evaluations was supported by ACCT (1986), Gleazer (1985), Seitz (1980), Tatum (1985) and Williams (1977a) .

The majority of the chief executive officers played a significant role in the development and initiation of their evaluation policies and practices.

The majority of the chief executive officers were evaluated annually and at a predetermined time using no written policies or procedures and were evaluated in similar settings with combination formats and with the ongoing basis format, which has no format. No specific patterns were found on the form and content of the evaluations, because of the use of combination formats and the uniqueness of each chief executive officer's evaluation.

It was concluded that the chief executive officers are satisfied with their annual evaluations and with the combination formats and settings in which they occur because they play a major role in the development and initiation of their evaluations. The reasons no 
significant themes exist among the form and content of the chief executive officers' evaluations are the individual differences among the chief executive officers, governing boards and the district environments.

\section{Informal Feedback Channels}

Use of informal feedback channels by governing boards are a part of the informal evaluation of a chief executive officer (Nason, 1984a; Wood 1984) and faculty are generally the main constituency to use these channels with governing boards. Both Beaudoin (1986) and Kerr and Gade (1986) found that faculty do not want input to the chief executive's evaluation to show support for the chief executive; and therefore, governing boards are cautioned to weigh carefully the significance of the input, especially if it is given anonymously (Arden, 1984; Kauffman, 1980). The majority of the governing boards used some form of informal feedback channels from the various constituencies with no evidence of an effect on the chief executives' evaluations.

It was concluded that the governing boards did receive input regarding the chief executive officers through informal channels from other groups, especially the faculty, but the effect this input has on the chief executives' evaluations does not result in predictable patterns. By keeping the input on the chief executive officers' evaluations informal, the governing boards remain in control of the chief executives' evaluations instead of the constituencies who want to provide input. 
Bureaucratic Purposes

The two professional trustee organizations (Association of Community College Trustees and the Association of Governing Boards) recommended that the primary purpose for the evaluation should be the improved performance of the chief executive officers and that contract renewal should be handled separately (ACCT, 1986; Nason, 1984a), but based on the perceptions of the chief executive officers interviewed, the governing boards were not following these recommendations.

The majority of the governing boards used bureaucratic purposes as the main purpose for evaluating their chief executive officers.

The majority of the chief executive officers described multiple purposes for their evaluations, but their contract extension, which is a bureaucratic purpose was considered to be the primary purpose. The improvement of the chief executives' performance was not considered to be the main purpose for their evaluations per se.

It was concluded that the governing boards' primary purpose for evaluating the community college chief executive officers is bureaucratic and the reason that the boards may consider the extension of the chief executives' contracts as a positive indicator of and reward for good performance is that they assume the contract extensions will motivate the chief executives to continue improving or at least maintaining their performance. 
Criteria Used for Evaluations

"The varying roles of the president compel multiple criteria for evaluation" (Nordvall, 1979, p. 43) . Also, the chief executive officer is evaluated on individual performance as well as institutional performance (Dick, 1978; Drucker, 1974; Fisk \& Richardson, 1979; Richman \& Farmer, 1977).

The majority of the governing boards used criteria which were considered appropriate by the chief executive officers. The majority of the chief executive officers perceived they were evaluated using both formal and informal criteria.

The community college chief executives feel the multiple criteria that are used to evaluate them are appropriate because they understand they must maintain a relationship with their board and the board will evaluate them on both individual and institutional performance criteria.

\section{Formal Evaluation Practices}

The majority of the 20 chief executive officers' evaluations by the governing board would not be described as formal by Nason (1984a, p. 14) because formal input from on-campus constituencies was not a part of the evaluations. Also there can be structure to both informal and formal evaluations (Wheat, 1981).

The majority of the chief executive officers perceived their governing boards used formal evaluation practices. 
It was concluded that the community college chief executive officers perceive their governing board evaluations to be formal when they are scheduled regularly and usually annually, are in some written evaluation format and are contrasted to their on-going basis evaluations which have no format. It would appear these elements, which provided structure to the evaluations cause the chief executive officers to feel that their annual evaluations are formal.

The summary conclusions for Research Question No. 1 are as follows:

1. The majority of the chief executive officers are satisfied with theix annual governing board evaluation policies and practices which are generally unwritten, occur in combination formats and settings and are based on criteria considered by the chief executives to be appropriate.

2. The annual evaluations are viewed as formal by the majority of the chief executives because the practices have more structure than their on-going basis format.

3. The majority of the governing boards use bureaucratic purposes and informal feedback channels for constituency input for the evaluations and thereby retain control of the policies and practices and the outcomes of the evaluations.

4. The lack of general patterns for governing board evaluation policies and practices is explained by the 
individual differences among the chief executive officers, governing boards and the district environments.

Research Question No. 2

Research Question No. 2 of the study was: "Which California community college chief executive officer evaluation policies and practices, of the 20 selected districts, are perceived by the chief executive officers to effectively improve their performance?" Governing Boards' Evaluator Role

One of the primary roles of a governing board is to evaluate the chief executive officer (Anderson, 1975; Dressel, 1981). "No board member can assess a president with fairness and honesty without knowing what the trustee's job is all about" (Tatum, 1985, p. 15).

The majority of the chief executive officers felt that their boards accepted the responsibility to evaluate them and were comfortable in their role as evaluator and that the boards' evaluations had been fair.

Since the majority of the chief executives perceived their evaluations were handled in a fair manner, it was concluded that the majority of the community college governing boards understand their evaluation responsibilities to the extent that they have evaluated their chief executives fairly. Effective Evaluation Policies

An effective evaluation of a community college chief executive helps the individual improve his or her job performance and satisfaction (C. F. Fisher, 1978, p. 7). 
As Dressel (1976) recommended, the evaluation of the chief executive officer "must. take into account the peculiar character of higher education governance, the specific nature of the particular institution and the external pressures bearing on it" (p. 388).

The majority of the chief executive officers perceived their evaluation policies to be effective because their performance improved as a result of the evaluations, but no themes evolved on what was considered an effective policy. The majority of the chief executive officers believed evaluation should change their behavior or actions and, in fact, they had changed their behavior or actions because of the governing boards' evaluations.

The reason there are no specific models on effective governing board evaluation policies for all California community college chief executive officers is because there are too many environmental variables and individual differences among the chief executive officers and the governing boards which cause each policy to be unique. Effective Evaluation Practices

There were no similarities among governing board evaluation practices which were identified as effective by the chief executive officers.

The reason no general patterns exist on what the California community college chief executive officers consider to be effective governing board evaluation practices is because practices are peculiar to each district and their chief executive. 
The summary conclusions for Research Question No. 2 are as follows:

1. The majority of the governing boards accept and understand the responsibility for evaluating their chief executive and evaluate their chief executive officer fairly.

2. The majority of the chief executive officers perceive their governing board evaluation policies and practices to be effective because they change their behavior or actions and improve their performance as an outcome of the evaluations.

3. No one governing board evaluation policy or practice is identified as effective by the chief executive officers due to the uniqueness of each district environment and the differences among the chief executive officers and the governing boards.

\section{Research Question No. 3}

Research Question No. 3 for the study was: "What factors contribute to effective evaluations by improving the performance of California community college chief executive officers, as perceived by the chief executive officer?"

\section{Factors Affecting}

\section{Chief Executive Officers' Evaluations}

Several factors were examined to determine the possible influence on the governing boards' evaluations of the chief executive officers; however, it was found that 
the presence of these evaluation factors did not necessarily result in effective evaluations. Internal and External District Environments

The challenge for the college chief executive officers in the 1980s is to manage their environment (McCorkle \& Archibald, 1982, p. xvii). Also, the evaluation of how effectively chief executive officers manage their environment must be based to some extent upon some [governance] model which characterizes a particular institution (Dressel, 1976, p. 382).

The internal and external district environments do have an influence on the chief executive officers' evaluations, but the degree of the effect is unique to each district only.

The multiple variables present in each of the chief executive officers' internal and external district environments, governance structures and their complexity and geographical location and community expectations, affected the chief executive's evaluation. Because each district was unique, the effect was unique to that district and its community college chief executive officer's evaluation.

It was concluded that no accurate predictions can be made on how California community college chief executives' governing board evaluations will be affected by the conditions present in their district environments, only that these conditions will influence the evaluation. 
Chief Executive Officers' Experience, Contracts and Job Descriptions

The chief executive officers' experience in their positions, type and length of their contracts and their job descriptions have no significant effect on their evaluations.

Experience was not a factor in the 20 chief executives' evaluations because the research design delineated a sample with 15 of 20 chief executives having more than 5 years of experience in their positions.

The type and length of the contract have no apparent effect on the California community college chief executive officers' governing board evaluations because the 20 chief executive officers' contracts were so similar, possibly due to the California Education code contract stipulations.

Both Klingner (1980, p. 257) and Tyer (1982, p. 208) stated that tasks performed by management are more complex and interrelated, which causes the evaluation of managerial performance to be different from employee evaluation, i.e. less defined and more difficult to perform. A prerequisite component of most employee evaluations is the job description (Howell \& Dipboye, 1982, p. 178); but at the chief executive officer's level of the organization, the individual's performance encompasses both the organization's and management team's performance as a whole (Drucker, 1974), which does not easily fit a job description format. The majority of the chief executive officers' job 
descriptions have no significant influence on their governing board evaluations.

It was concluded that the lack of a relationship between the community college chief executive officers' evaluations and their job descriptions is no different than it would be for any other chief executive officer of an organization.

\section{Chief Executive officers' Roles and Evaluation Criteria}

The evaluation of a chief executive officer should be a process of clarifying the role expectations (Farmer, 1979, p. 4). And as Kauffman (1980) discussed, the role of a chief executive is an insecure one.

The chief executives' self-described roles in relation to their perceptions on the criteria which should be used to evaluate them may be significant when the roles and criteria used are not congruent.

The majority of the chief executives perceived they had dual roles which occurred because of their differing relationships with the community, the governing board and the district faculty and staff. With each role comes certain expected behaviors and the result for the chief executive is a position with multiple and complex roles.

For the majority of the chief executives, the criteria used by the governing board to evaluate them did fit their perceptions of their roles. When the chief executive officer's self-described roles did not fit the criteria the governing board actually used in the evaluation, however, an incongruence occurred which did affect the chief 
executive officer's evaluation. Also, having multiple and complex roles with no real agreement on which role or roles (and resulting criteria) will be evaluated by the governing board may be one of the reasons the chief executive officers lack security in their positions.

Community college chief executive officers' perceptions of their roles and their governing boards' evaluation criteria must be in congruence and when they are not, the impact can be a negative evaluation for the individual chief executive officer.

\section{Governing Board Membership and Chairs}

Elected boards tend to represent the people who elect them and tend to have a special sense of control over the chief executive officer (Kerr \& Gade, 1986, p. 110). "Given the turnover on boards of trustees, especially in states with district election, maintaining sound relationships is an incessant challenge" (Ingram, 1979, p.75). The chief executive officer must cope with the fact that each board member has his or her own distinctive understanding of the institution's mission; and therefore, his or her own expectations of the president's performance (Munitz, 1978, p. 12). And as Brown (1984) stated, "the success of the periodic assessment [evaluation of the chief executive] may well center more on the nature of the individuals involved than the system itself" (p. 4).

The changes in governing board membership and board chair positions may have an effect on the chief executive officers' evaluations depending upon the individual board 
members. This conclusion becomes problematic for a California community college chief executive officer and points to the need for the chief executive officer to maintain a good relationship with his or her governing board as $a$ whole and with individual board members if at all possible. The chief executive officers in this study referred to this situation as "counting your votes." The majority of the votes obviously must be in favor of the chief executive or the working relationship will deteriorate with the final outcome being a negative evaluation and possibly a decision to not renew the chief executive officer's contract. This condition is another example of the insecure position of a California community college chief executive officer.

Governing Board Stability and Political Behavior

"The governing board itself is a major factor in the president's effectiveness or lack of effectiveness" (Kauffman, 1980, p. 94). Publicly elected governing boards, found in california community colleges, tend to be more political public servants than boards that are appointed (Kauffman, 1980; Kerr, 1984, Nason, 1984a). A supportive board is needed to promote a unity of purpose between the chief executive and the board (Gilley, Fulmer \& Reithlingshoefer, 1986, p. 12). These authors' observations suggested that a relationship does exist between a boards' stability and political behavior and does have an influence on the chief executive's evaluation. 
The chief executive officers' descriptions of their boards' stability and political behavior produced no significant relationship between the description and the effect on the chief executive's evaluation. This relationship, then, was not a significant one for the California community college chief executive officers. No themes evolved based on a board's stability and political behavior to predict the effect on the chief executive's evaluation.

\section{Factors Contributing to Effective}

\section{Chief Executive officer Evaluations}

"Without a sound relationship with the governing board, the president cannot be effective" (Kauffman, 1980, p. 52). There must be mutual respect and trust between the board and the chief executive officer to insure a higher level of performance for the institution (Tatum, 1985, p. 18). An effective evaluation requires open communication (Fisk \& Richardson, 1979, p. 342). "Clearly, evaluation would be impossible or meaningless without some explicit specification of what one is expected to do" (Howell \& Dipboye, 1982, p. 178). A person being evaluated needs to have a clear understanding of what needs to be done and progress on those expectations needs to be communicated frequently (King, 1984, p. ix). Each of these observations, from authors representing the educational perspective and the personnel administration perspective, are manifested in the same two governing board evaluation factors identified by the majority of the chief executive officers. 
The relationship between the chief executive officer and the governing board and the chief executive's understanding of the governing board's expectations and/or goals and objectives were identified by the chief executive officers as the two factors which contributed to their improved performance. These two factors were the two constant variables that were foundational to several of the findings in the study. These factors are necessary primarily for the California community college chief executive officers to perform their responsibilities in their positions and as a result they are the factors which contribute to their governing board evaluations being effective. The format or the formality of the evaluations is not what makes the evaluations effective.

The summary conclusions for Research Questions No. 3 are as follows:

1. The internal and external district environments do have an influence on the chief executive officers' evaluations, but the effect becomes unique to each chief executive because each district's environment is unique.

2. The chief executive officers' experience, contract and job description did not have an effect on the majority of the chief executive officers' evaluations.

3. The chief executive officers' self-described roles and their governing boards' evaluation criteria must be in congruence or the result can be a negative evaluation for the individual chief executive officer. 
4. The changes in governing board membership and board chair positions may have an influence on the chief executive officers' evaluations depending upon the individual board members.

5. The majority of the chief executive officers' descriptions of their boards' stability and political behavior does not result in predictable evaluation outcomes.

6. The majority of the chief executive officers recognize that having a positive relationship with the board and understanding the board's expectations will result in effective evaluations and improved performance. These two factors determine whether the governing boards' evaluations of the chief executive officers are effective and not the format or the formality of the evaluations.

\section{Major Conclusions of the study}

The major conclusions of this study are as follows:

1. The majority of the California community college chief executive officers in this study perceived their governing board evaluations to be effective. The effectiveness of the evaluations, as identified by the chief executive officers, was based on the presence of two factors: (a) a good relationship between the governing board and the chief executive which resulted in trust, openness and on-going communication; and (b) an understanding by the chief executive officer of the governing board expectations and/or goals and objectives. 
2. Each district is unique because of the variables of internal and external district environments, congruence between chief executives' self-described roles and the criteria used for the evaluation, and the governing board and individual governing board members and the interaction among these variables, implying that California chief executive officers' evaluations are unique and situational to each district. The variables present in each of the 20 California community colleges of this study produced a different governing board evaluation for each chief executive officer and that occurred because the evaluation reflects the history and environment of the institution of which the chief executive and governing board are a part. These variables along with the finding that the chief executive officers played a significant role in developing their evaluations also account for the variety of forms and contents of the evaluations.

3. The form and the content of the governing boards' evaluations of the California community college chief executive officers are not what causes the evaluations to be effective. What is implied in this conclusion is that the activity of seeking a model for evaluating California community college chief executive officers is probably a non-productive activity because the ideal instrument, policy or practice will not be found. Nor should there be a statewide system to evaluate community college chief executive officers for if that occurred the purpose would 
clearly not be for improving the performance of the chief executive officer.

4. Locally elected governing boards of the California community colleges evaluate their chief executives primarily for bureaucratic purposes, which means the boards' primary concerns are the management of the districts and the determination of extending the chief executive officers' contracts. The outgrowth of this situation, however, is that the majority of the chief executive officers still feel their governing board evaluations are effective because their performance improved.

\section{Recommendations}

Based on the findings and conclusions of the study, the following recommendations are made:

1. California community college chief executive officers and governing boards should not be looking for models of chief executive officer evaluations, but instead be looking for methods and processes appropriate to their district environments which will enhance the relationship between the governing board and chief executive officer and increase the chief executive's understanding of the governing boards expectations.

2. Only California community college governing boards should evaluate the chief executive officers and any input received from other constituencies should be viewed as opinions and perceptions of the chief executive's behavior and not as an evaluation. 
3. There should be a shift in emphasis away from implementing more formal policies and practices for evaluating California community college chief executive officers which may involve formal input from all the constituencies, and instead, the emphasis should be on maintaining the governing board evaluation policies and practices which enhance continuous and open communication between the california community college chief executive officers and their governing boards.

4. A future study on the behaviors which contribute to good governing board and chief executive officer relationships that can be identified during the selection process of the chief executive officer by the governing board might reduce the high turnover rate in California community college chief executive officers.

5. A future study designed to analyze the perceptions of the California community college governing boards on how they view their policies and practices for evaluating their chief executive officers would validate the findings of this study.

The findings of this study have been prepared to assist California community college governing boards and chief executive officers understand the theoretical foundations of the evaluation policies and practices they presently use and, also, to provide the necessary information for making future decisions on the evaluation of the chief executive officer. 


\section{REFERENCES}




\section{References}

Aldag, R. J. \& Stearns, T. M. (1987) . Manaqing. Cincinnati, ohio: Southwestern.

Allison, G. T. (1984). Public and private administrative leadership: Are they fundamentally alike in all unimportant respects? In T. J. Sergiovanni \& J. E. Corbally (Eds.), Leadership and orqanizational culture: New perspectives on administrative theory and practice (pp. 214-239). Chicago: University of Illinois Press.

Anderson, G. L. (1975). The evaluation of academic administrators: Principles, processes and outcomes. University Park, PA: Pennsylvania State University, Center for the study of Higher Education.

Arden, E. (1984, September 12). Reviewing the performance of college presidents. The Chronicle of Higher Education, p. 72 .

Argyris, C. (1980). Educating administrators and professionals. In C. Argyris \& R. M. Cyert (Eds.), Ieadership in the 90s: Essays on higher education (pp. 1-38). Cambridge, MA: Institute for Educational Management, Harvard University.

Association of Community College Trustees. (1986). Presidential evaluation for community colleges. (Report of the ACCT Special Committee Presidential Evaluation, chaired by J. Tatum). Washington, D.C.: Author.

Astin, A. W. \& Scherrei, R. A. (1980) . Maximizing leadership effectiveness: Impact of administrative style on faculty and students. San Francisco: JosseyBass.

Bahar, H. (1979). Presidential evaluation. ACCT Trustee Quarterly, $\underline{3}(4), 1-5$.

Baldridge, J. V. (1971). Power and conflict in the university. New York: John Wiley.

Beaudoin, D. B. (1986). Formal procedures and informal influences: Assessing a college president's performance. (Doctoral Dissertation, Harvard University, 1986). Dissertation Abstracts International, 47, 2904A.

Benezet, L. T., Katz, J. \& Magnusson, F. W. (1981). Style and substance: Leadership and the college presidency. Washington, D. C.: American Council on Education. 
Bennis, W. G. (1976). The unconscious conspiracy: Why leaders can't lead. New York: AMACOM.

Block, M. H. (1979) . State University of New York: Presidential evaluation. In C. H. Farmer, Administrative evaluation: Concepts, methods, cases in higher education (pp. 142-154). Richmond, VA: Higher Education Leadership and Management society.

Bolman, F. dew. (1965). How college presidents are chosen. Washington, D. C.: American Education Council.

Bolman, L. G. \& Deal, T. E. (1984). Modern approaches to understanding and manaqing organizations. San Francisco: Jossey-Bass.

Brenner, M. , Brown, J., \& Canter, D. (1985). The research interview. London: Academic Press.

Brewster, K., Jr. (1979, April). The politics of academia. School and Society, 2, pp. 211-214.

Brown, J. E., III. (1984). Point of growth. Change, 16(8), $4-5$.

Burns, J. M. (1978) . Leadership. New York: Harper Calophon.

California Association of Community Colleges. (1987) CACC Directory. Sacramento, CA: Author.

California Education Code of 1983, Vol. 3, Title III, Div. 7 .

Carbonne, R. F. (1981). Presidential passages. Washington, D. C.: American Council on Education.

Carlisle, H. M. (1987). Management essentials: concepts for productivity and innovation (2nd ed.). Chicago: Science Research Associates.

Cashin, W. E. (1984, October 10). Providing information about a president: Not the same as evaluating performance. The Chronicle of Higher Education, p. 38 .

Certo, S. C. (1983). Principles of Modern Management (2nd ed.). Dubuque, Iowa: Wm. C. Brown.

Chief Executive officers of California Community colleges. (May, 1987) . Chief Executive Officers Directory. Los Altos Hills, CA: Foothill-DeAnza Community College District.

Cleveland, H. (1985). The costs and benefits of openness: Sunshine laws and higher education. Washington, D. C.: 
Association of Governing Boards of Universities.

Cohen, A. M. \& Brawer, F. B. (1982). The American community college. San Francisco: Jossey-Bass.

Cohen, M. D. \& March, J. G. (1986). Leadership and ambiquity (2nd ed.). Boston: Harvard Business School.

Cyert, R. M. (1980). Managing universities in the 1980s. In C. Argyris \& R. M. Cyert (Eds.), Leadership in the 80s: Essays on higher education (pp. 39-66). Cambridge, MA: Institute for Educational Management, Harvard.

Cyert, R. M. (1979). Governance and administration of the university. In F. dew. Bolman \& C. C. Walton (Eds.), Disorder in Higher Education (pp. 90-117). Englewood Cliffs, New Jersey: Prentice-Hall.

Daft, R. L. (1988) - Management. Chicago: Dryden.

Dexter, L. A. (1970) . Elite and specialized interviewing. Evanston, IL: Northwestern University.

Dick, I. (1978). A rationale and suggested procedures for the evaluation of senior administrators. Tucson, AZ: University of Arizona. (ERIC Document Reproduction Service No. ED 176830 )

Douglas, J. D. (1976) . Investigative social research. Beverly Hills, CA: Sage.

Dressel, P. L. (1981). Administrative leadership. San Francisco: Jossey-Bass.

Dressel, P. L. (1976). Handbook of academic evaluation: Assessing institutional effectiveness, student progress, and professional performance for decisionmaking in higher education. San Francisco: JosseyBass.

Drucker, P. F. (1974). Management: Tasks, responsibilities, practices. New York: Harper \& Row.

Drucker, P. F. (1967) . The effective executive. New York: Harper \& Row.

Evans, N. D., Mears, G. L., Wattenbarger, J. L. (1979) . Evaluating the performance of a community college president. In G. E. Potter (Ed.), Handbook for community colleges and technical institute trustees (pp 61-78).

Farmer, C. H. (1979) Administrator evaluation: Concepts, methods, cases in higher education. Richmond, VA: Higher Education Leadership and Management Society. 
Fielding, N. G. \& Fielding, G. L. (1986). Linking Data. Beverly Hills, CA: Sage.

Fisher, C. F. (1978). The evaluation and development of college and university administrators. In J. A. Shtogren (Ed.), Administrative development in higher education. The state of the art: Volume one. Richmond, VA: Higher Education Leadership and Management Society.

Fisher, J. L. (1984) . Power of the presidency. New York: Macmillan.

Fisher, J. L. \& Quehl, G. H. (1984). Presidential assessment: Obstacles to leadership. Change, 16(4), 5-7.

Fisk, C. \& Richardson, R. C., Jr. (Fall 1979). Presidential evaluation: The state of the art. Iiberal Education, $65,341-354$.

Gephart, W. J., Ingle, R. B., \& Potter, J. N. (Eds.) . (1975) . The evaluation of administrative performance: Parameters, problems and practices. NSPER: 75. Bloomington, In: Phi Delta Kappa.

Gilley, J. W., Fulmer, K. A., \& Reithlingshoefer, S. J. (1986) . Searching for academic excellence: Twenty college and universities on the move and their leaders. New York: MacMillan.

Glaser, B. G. \& Strauss, A. L. (1967). The discovery of grounded theory. New York: Aldine.

Gleazer, Jr. E. J. (1985). Governance and the shifting role of the board of trustees. In W. L. Deegan \& J.F. Gollattscheck (Eds.), Ensuring Effective Governance (pp. 41-51). New Directions for Community Colleges, No. 49. San Francisco: Jossey-Bass.

Goetz, J. P., \& LeCompte, M. D. (1984). Ethnography and qualitative design in educational research. New York: Academic Press.

Guba, E. G., \& Lincoln, Y. S. (1981). Effective evaluation. San Francisco: Jossey-Bass.

Hammersley, M. , \& Atkinson, P. (1984) - Ethnography: Principles in practice. London: Tavistock.

Hanley, D. L. (1975, March/April). Evaluating a president. AGB Reports, 17, 42-47.

Hansen, C. I. (1984). It seemed like a good idea at the time. Change, 16(8), 6-8. 
Harvey, I. J. (1976) Manaqing Colleges \& Universities by objectives. Littleton, $\mathrm{CO}$ : Ireland Educational Corporation.

Hays, G. D. (1976, November/December). Evaluating a president: Criteria and procedures. AGB Reports, 18, $41-46$.

Henderson, L. G. (1976). Some recommended quidelines for the evaluation of a community college president. Tallahassee, FL: Florida state Department of Education, Division of Community Colleges. (Eric Document Reproduction Service No. ED 189 534)

Howell, W. C. \& Dipboye, R. L. (1982). Essentials of industrial and organizational psychology. Homewood, IL: Dorsey Press.

Hubert, W. P. (1986). The evaluation of the college and university president. (Doctoral Dissertation, Claremont Graduate School, 1985). Dissertation Abstracts International, 47, 1550A.

Ingram, R. T. (1979). The marriage of presidents and boards. In R. E. Lahti (Ed.), Manaqing in a new era (pp. 73-82). New Directions for Community Colleges, No. 28. San Francisco: Jossey-Bass.

Kauffman, J.F. (1980). At the pleasure of the board. Washington, D. C.

Kauffman, J. F. (1978). Presidential assessment and development. In C. F. Fisher (Ed.), Developing and evaluating administrative leadership (pp. 59-69). San Francisco: Jossey-Bass.

Kerr, C. (1984). Presidents make a difference. (Report of the Commission on strengthening Presidential Leadership). Washington, D. C.: Association of Governing Boards of Universities and Colleges.

Kerr, C. \& Gade, M. L. (1986). The many lives of academic presidents: Time, place and character. Washington, D. c.: Association of Governing Boards of Universities and colleges.

Kerr, C. \& Gade, M. (1981). Current and emerging issues facing American higher education. In P. G. Altbach \& R. O Berdahl (Eds.), Higher education in American society (pp. 111-129). Buffalo, NY: Prometheus.

Kidder, L. H. (1981). Qualitative research and quasiexperimental frameworks. In M. B. Brewer \& B. E. Collins (Eds.), scientific inquiry and the social sciences (pp. 226-256). San Francisco, CA: JosseyBass. 
King, P. (1984) - Performance planning and appraisal: A how to book for managers. New York: McGraw-Hill.

Kirk, J., \& Miller, M. L. (1986). Reliability and validity ir. qualitative research. Beverly Hills, CA: Sage.

Klingner, D. E. (1980) . Public personnel management: Contexts and strategies. Englewood Cliffs, NJ: Prentice Hall.

Lahti, R. E. (1973). Innovative college management. San Francisco, CA: Jossey-Bass.

Landy, F. Zedeck, S. \& Cleveland, J. (Eds.). Performance measurement and theory. New Jersey: Lawrence Erlbaum.

Lombardi, J. (1981). The trustee's role in the evaluation of the president. ACCT Trustee Quarterly, $\underline{5}(1), 15-21$.

Losak, J. (1975, April). The myth of rational evaluation. Paper presented at the annual meeting of the American Association of Community and Junior Colleges, seattle, WA. (Eric Document Reproduction Srvice No. ED 112 993)

March, J. G. (1984). How we talk and how we act: Administrative theory and admiistrative life. In T. J. Sergiovanni \& J. E. Corbally (Eds.), Leadership and organizational culture: New perspectives on administrative theory and practice (pp. 18-35) . Chicago: Univesity of Illinois Press.

Massie, J. G. \& Douglas, J. (1985) . Manaqing: A contemporary introduction (4th ed.). Englewood cliffs, NJ: Prentice Hall.

McCorkle, C. O., Jr. \& Archibald, S. O. (1982) . Manaqement and leadership in higher education. San Francisco: Jossey-Bass.

Michael, W. (1985). [Superintendent (chancellor) evaluation instruments used by california community Colleges]. Unpublished raw data.

Miller, R. I. (1979) . The assessment of college performance. San Francisco: Jossey-Bass.

Millett, J. D. (1980). Management, governance and leadership. New York: AMACOM.

Mooney, C. J. (1988, March 30). More college chief executives are being chosen for non-academic skills, some observers say. The Chronicle of Higher Education, pp. A15-A16.

Mostyn, B. (1985). The content analysis of qualitative research data: A dynamic approach. In $M$. Brenner, $J$. 
Brown, \& D. Canter. The research interview (pp. 115145). London: Academic Press.

Munitz, B. (1980). Reviewing presidential learexship. In R. T. Ingram and Associates (Ed.), Handbook of college \& University Trusteeship (pp. 377-404). San Francisco: Jossey-Bass.

Munitz, B. (1978). Strengthening institutional leadership. In C. F. Fisher (Ed.), Developing and evaluating administrative leadership (pp. 11-21). San Francisco: Jossey-Bass.

Nason, J. W. (1984a). Presidential assessment: A quide to the performance of chief executives. Washington, D. C.: Association of Governing Boards of Universities \& Colleges.

Nason, J. W. (1984b) . Presidential search: A quide to theprocess of selecting and appointing college and university presidents (rev. ed.). Washington, D.C.: Association of Governing Boards of Universities \& Colleges.

Nason, J. W. (1982). The nature of trusteeship: The role and responsibilities of college \& university boards. Washington, D. C.: Association of Governing Boards of Universities \& Colleges.

Nason, J. W. (1981). Presidents and governing boards. In P. G. Altbach \& R. O. Berdahl (Eds.), Higher education in American society (pp. 253-268). Buffalo, NY: Prometheus.

Nason, J. W. (1980). Presidential Search: A quide to the process of selecting \& appointing college \& university presidents. Washington, D.C.: Association of Governing Boards of Univesities \& Colleges.

Nordval1, R. C. (1979). Evaluation and development of administrators (AAHE-ERIC/HIgher Education Research Report No. 6). Washington, D. C.: American Association of Higher Education.

Parekhi, S. B. (1977). Presidential evaluation equals long-range planning. Planning for Higher Education, $\underline{6}$.

Patton, M. Q. (1980) . Qualitative evaluation methods. Beverly Hills, CA: Sage.

Paxton, D. R. \& Thomas, D. L. (1977). College president's role performance and faculty satisfaction. Research in Higher Education, I, 341-353.

Peters, T. J. \& Waterman, R. H., Jr. (1982). In search of 
excellence: Lessons from America's best run companies. New York: Harper \& Row.

Pocock, J. W. (1984). The board chairperson and the president. Washington, D. C.: Association of Governing Boards of Universities and Colleges.

Potter, G. E. (Ed.). (1979). Handbook for community college and technical institute trustees. Washington, D. C.: Association of Community collee Trustees.

Pullias, E. V., \& Wilbur, L. (1984). Principles and values for college and university administration. New York: Philosophy Library, Inc.

Rausch, E. (1980). Management in institutions of higher learning. Lexington, MA: D. C. Heath.

Rice, B. (1985, september). Performance review: The job nobody likes. Psychology Today, 31-36.

Richman, B. M. \& Farmer, R. N. (1977). Leadership, goals and power in higher education. San Francisco: JosseyBass.

Schafer, E. G. (1980, March). Board/president evaluation techniques. Paper presented at the meeting of the Association of Community College Trustees, Los Angeles, CA.

Scheidt, O. H. (1980). [A survey of chief executive officers in California]. Unpublished raw data.

Schwartz, H., \& Jacobs, J. (1979) . Qualitative sociology: A method to the madness. New York: Free Press.

Seitz, J. E. (1980). Evaluating your president objectively. ACCT Trustee Quarterly, $\underline{4}(1), 26-32$.

Sloma, R. S. (1980) . How to measure managerial performance. New York: MacMillian.

Spradley, J. P. (1979) . The ethnographic interview. New York: Holt, Rinehart, \& winston.

Surwill, B. J. \& Heywood, S. J. (1976) . Evaluation of college \& university top brass: The state of the art status report of AASCU member institutions. Washington, D. C.: American Association of state Colleges \& Universities.

Tatum, J. B. (1985). Active trusteeship for a changing era. In C. F. Petty (Ed.), Active Trusteeship for a changing era (pp.15-19). New Directions for Community Colleges, No. 15. San Francisco: Jossey-Bass. 
Thompson, D. (1981, Fall). Performance appraisal and the civil service reform act. Public Personnel Management Journal, 10, 281-288.

Tucker, A. \& Mautz, R. (1979). Presidential evaluation: An academic circus. Educational Record, 60, 253-260.

Tyer, C. B. (1982, Fall). Employee performance appraisal in American state governments. Public Personnel Management Journal, 11, 199-212.

Van Cleve, H. P. (1983). Evaluation of the community college president. ACCT Trustee Quarterly, I(2), 2526.

Vaughan, G. G. (1986) - The community college presidency. New York: American Council on Education/MacMillan.

Vaughan, G. G. (1985). The community college in America: A short history. Washington, D. C.: American Association of Community and Junior colleges.

Vaughan, G. B. \& Associates (1983). Issues for community college leaders in a new era. San Francisco: JosseyBass.

Volhontseff, T. (1987). An analysis of the board-chief executive officer partnership and its relationship to the evaluation of the chief executive officer in California community colleges. (Doctoral Dissertation, University of San Francisco, 1986). Dissertation Abstracts International, 47, 2432A.

Warren, M. W. (1982) . Performance management and management performance. In L. W. Frederiksen (Ed.), Handbook of orqanizational behavior management (pp. 539-564). New York: Wiley \& Sons.

Wattenbarger, J. I. (1983) . Evaluation of college administrators. In A. Smith (Ed.), Evaluating faculty and staff (pp.45-55). New Directions for Community Colleges, No. 41. San Francisco: Jossey-Bass.

Wattenbarger, J. L., Evans, N., Mears, G. L. (1979, February). Who's evaluating the president? Community and Junior College Journal, 8-10.

Wheat, M. W. (1981). Evaluation of the chief executive officer. ACCT Trustee Quarterly, $\underline{5}(4), 32-35$.

Williams, R. E. (1977a) - Presidential evaluation. Buffalo, N. Y.: State University of New York. (ERIC Document Reproduction Service No. ED 144 643)

Williams, R. E. (1977b) . Toward quality administration: Presidential assessment at Northern Virginia community 
college as a means of professional development for the president. Buffalo, NY: Department of Higher Education, state University of New York.

Wood, M. M. (1984). Crosscurrents and undercurrents in the trustee-president relationship. Educational Records, $\underline{65}(1), 38-42$. 
APPENDICES

159

Reproduced with permission of the copyright owner. Further reproduction prohibited without permission. 
APPENDIX A

Interview Request Cover Letter

160

Reproduced with permission of the copyright owner. Further reproduction prohibited without permission. 


\section{Southwestern \\ College}

January 12,1988

Dear

Your assistance is requested for conducting my doctoral study at the University of San Diego titled, AN ANALYSIS OF SELECTED CALIFORNIA COMMUNITY COLLEGE CHIEF EXECUTIVE OFFICERS' PERCEPTIONS OF THE EFFECTIVENESS OF DISTRICT GOVERNING BOARD EVALUATION PRACTICES.

This study examines an area of considerable interest and importance in community college management and I believe that the results of the study will make an important contribution to the literature in the field and to the California community college chief executive officers.

You are one of the twenty chief executive officers randomly selected to be interviewed for this study. The interview should take place at your office within the next five weeks, depending upon your availability for a personal and confidential interview. I will be contacting your office within the next few days to schedule your interview. Should you have any questions prior to my contacting you, please feel free to reach me at Southwestern College (619) 421-6700, ext. 278.

I look forward to our interview and my visit to your district.

sincerely,

Sherrill L. Amador, Dean

Business Division

$S-5684$ 


\section{APPENDIX B}

Letter of Support for Interview 
JANUARY 11, 1988

DEAR

I AM WRITING ON BEHALF OF SHERRILL AMADOR, DEAN, BUSINESS DIVISION AT SOUTHWESTERN COLLEGE. SHERRILL IS COMPLETING HER DOCTORAL STUDY IN AN AREA WHICH IS OF GREAT INTEREST TO CHIEF EXECUTIVE OFFICERS OF COMMUNITY COLLEGES-EVALUATION.

SHERRILL'S DISSERTATION TOPIC, "AN ANALYSIS OF SELECTED COMMUNITY COLLEGE CHIEF EXECUTIVE OFFICERS' PERCEPTIONS OF THE EFFECTIVENESS OF DISTRICT GOVERNING BOARD EVALUATION PRACTICES", MAY PROVE TO BE OF GREAT ASSISTANCE TO CHIEF EXECUTIVE OFFICERS AND BOARDS.

BOTH THE GOVERNING BOARD AND I SUPPORT SHERRILL'S EFFORTS AND HAVE GRANTED HER A SABBATICAI LEAVE TO COMPLETE HER STUDY.

I HOPE THAT YOU WILL FIND TIME IN YOUR BUSY SCHEDULE TO ASSIST SHERRILL BY GRANTING HER TIME FOR A SHORT INTERVIEW SESSION.

I WILI GREATLY APPRECIATE ANY CONSIDERATION YOU ARE ABLE TO GIVE SHERRILL.

SAMCERELY,

JOSEPH M. CONTE

SUPERINTENDENT/PRESIDENT

JMC : AR

A20863 
APPENDIX C

Structured Interview Questions 


\section{Structured Interview Questions}

Interviewer: state the purpose of the study. Ask the Chief Executive officer to make a distinction in his/her responses between actual policy and procedures and the practices that occur. Ask for all available documentation. Determine the length of service of the interviewee as chief executive officer of the district and as an administrator. Determine the characteristics of the governing board related to size and length of service of each board member.

Question 1. Describe the process by which your board presently evaluates you. Please be specific as to written and unwritten policies and procedures, formal criteria, timelines, instruments and formats.

a. How does your job description relate to your evaluation?

b. How do the formal criteria that are used in your evaluation square with what the board members indicate they are concerned with?

c. In the absence of formal criteria, what are the processes and dynamics of your evaluation?

d. Has there ever been a doubt in your mind where you stand with the board relative to your job performance?

e. What has been the purpose for your board evaluation or what is your evaluation used for by the board?

f. Do you feel your evaluation by the board has really changed your behavior or actions? Do you feel your board evaluation is really suppose to change your behavior or actions?

g. As a result of your evaluation, how specific are the board's suggestions for improving your performance?

h. Has the content and form of your evaluation changed over the length of your service in this position?

Question 2. Who, other than the Board, is involved in your evaluation? Classify who they may be.

If any other groups or individuals than the board are involved, ask these questions: input?

a. Are formal or informal channels used for their

b. How do you feel about their input to your 
evaluation? board?

c. How much importance is placed on their input by the

d. In the past, have you changed your behavior or actions prior to or after the evaluation because of input from these individuals or groups? How and why?

e. Who do you feel is the most knowledgeable about your performance as the chief executive officer?

Question 3. Are there any unique characteristics about your district which affect your evaluation? What are they and how has the board responded to them?

a. Is your board under pressure to evaluate you in a more formal, public way than they do now? Why? policy?

b. Who initiated or developed your present evaluation

c. Do you feel the board is comfortable in their role as your evaluator? Why or why not?

d. Do you feel your evaluation policy or board evaluation practices have been fair? Why or why not?

Question 4. What components or elements of your evaluation have been the most effective in improving or affecting your performance?

a. If you could start now, what type of evaluation policy would you develop and why do you think it would be effective?

b. What do you feel is the most important factor in assessing the performance of a chief executive officer? How does this square with your formal or informal evaluation? Would you have responded differently at other times in your length of service and why?

Is there any thing else you would like to say to contribute to the worth of this study? 


\section{APPENDIX D \\ Informed Consent Form}

167

Reproduced with permission of the copyright owner. Further reproduction prohibited without permission. 


\section{Informed Consent Form}

\section{Sherrill L. Amador University of San Diego \\ Dissertation study}

I have heard the explanation of this doctoral study entitled, "An Analysis of Selected California Community college Chief Executive Officer's Perceptions of the Effectiveness of District Governing Board Evaluation Practices" and understand that my participation is entirely voluntary.

It is understood that my answers will be reported anonymously and that my name will never be publicly associated with the study without my specific written consent.

I understand that the interviews will be tape recorded and I give my permission to Sherrill I. Amador to use direct quotations.

If excerpts from my interview are included in the dissertation, any publication, or in any discussion of this research, all identifying information will be disguised or deleted.

\section{Signature:}

Date:

Name:

Address :

Phone: 